Florida International University

FIU Digital Commons

FIU Electronic Theses and Dissertations

University Graduate School

11-19-1999

\title{
The perceived level of autonomy among drivers with spinal cord injuries
}

\author{
Alice Mary Giron \\ Florida International University
}

Follow this and additional works at: https://digitalcommons.fiu.edu/etd

Part of the Medicine and Health Sciences Commons

\section{Recommended Citation}

Giron, Alice Mary, "The perceived level of autonomy among drivers with spinal cord injuries" (1999). FIU Electronic Theses and Dissertations. 3941.

https://digitalcommons.fiu.edu/etd/3941

This work is brought to you for free and open access by the University Graduate School at FIU Digital Commons. It has been accepted for inclusion in FIU Electronic Theses and Dissertations by an authorized administrator of FIU Digital Commons. For more information, please contact dcc@fiu.edu. 


\section{FLORIDA INTERNATIONAL UNIVERSITY}

Miami, Florida

THE PERCEIVED LEVEL OF AUTONOMY AMONG DRIVERS

WITH

SPINAL CORD INJURIES

A thesis submitted in partial fulfillment of the

requirements for the degree of

MASTER OF SCIENCE

in

OCCUPATIONAL THERAPY

by

Alice Mary Giron

1999 
To: Dean Ronald Berkman

College of Health Sciences

This thesis, written by Alice Mary Giron, and entitled The Perceived Level of Autonomy Among Drivers with Spinal Cord Injuries, having been approved in respect to style and intellectual content, is referred to you for judgment.

We have read this thesis and recommend that it be approved.

Susan Kaplan

Alma Abdel-Moty

Pamela Shaffner, Major Professor

Date of Defense: November 19, 1999

The thesis of Alice Mary Giron is approved.

Dean Ronald Berkman College of Health Sciences

Dean Richard L. Campbell Division of Graduate Studies 


\section{DEDICATION}

First and foremost, I would like to thank God for making all things possible and for giving me so many blessings. I dedicate this thesis to my mom and dad for all of their love throughout my life and for being the best parents anyone could have asked for. Thank you for all of the things you have given me.

I would like to thank Gladicita and Carli for being the greatest siblings. To my abuelita for all of your strength. I am truly lucky to have the family I was given. Ever since I can remember, you have all supported me and taught me to strive for the very best. To Julian, for being my best friend and for believing in me. To my three nephews, Andre, Alexander and Gabriel for bringing so much happiness to all of our lives. To my two grandfathers and tio Carlos in heaven, thank you for watching over me.

To my wonderful friends Arlen, Yoli, Jackie, Raquel, Ashley, Alissa, and Jen for all of the good times and laughter we have shared. 


\section{ACKNOWLEDGMENTS}

I would like to thank the members of my committee, Pamela Shaffner for seeing me through, Susan Kaplan for your guidance, and Alma Abdel-Moty for all of your support and for being such an inspirational teacher. Judi Hamelburg, for truly caring about me and the purpose of this study, you have been amazing. Mike Martelli, for also taking a strong interest in my study and for allowing it to become a reality. Paulette Johnson and Craig Haas, for their statistical expertise and for making this possible for me.

Dr. Hills, for all of your assistance on autonomy and for your encouragement. Nancy Cid, for being one of the kindest people I have ever met, thank you for all of your help.

I would also like to thank all of the participants in this study for teaching me that despite many set backs in life, there are many wonderful things to be enjoyed each day. You are all true heroes and I thank you for letting me share a part of your life with others. 


\title{
ABSTRACT OF THE THESIS \\ THE PERCEIVED LEVEL OF AUTONOMY AMONG DRIVERS \\ WITH SPINAL CORD INJURIES
}

by

\author{
Alice Mary Giron \\ Florida International University, 1999 \\ Miami, Florida \\ Professor Pamela Shaffner, Major Professor
}

The purpose of this study was to determine how autonomy is affected among individuals with spinal cord injuries by being able to drive again or for the first time, after participating in a driving rehabilitation program. Information was collected using a survey originally designed for the purpose of this study on driving-related autonomy. Fifty two surveys were included in this study and met the inclusive criteria. Analysis of the responses indicated that the majority of individuals in this study experienced a high level of autonomy after going through a driving rehabilitation program. The results showed that there was an increase in the number of subjects who did not drive before their injury, disability, or condition by $35.3 \%$, after participating in a driving rehabilitation program. It was also found that $76.9 \%$ of the subjects perceived that driving had improved their life by $100 \%$ on a daily basis after completing a driving rehabilitation program. The participants perceived driving as being very important in allowing them to remain or become autonomous, by being able to drive themselves to needed and desired locations. 


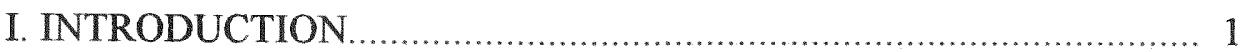

Significance of the Study.................................................................. 3

Statement of the Problem.................................................................... 3

Objective and Research Questions....................................................... 5

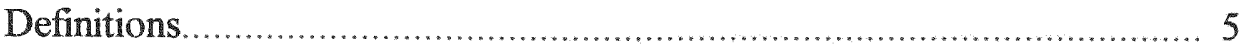

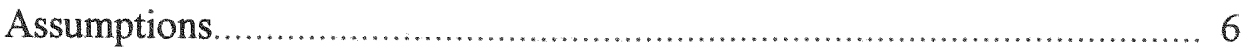

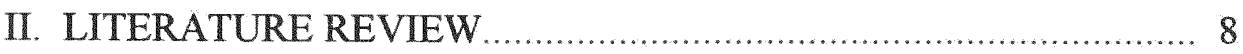
Autonomy

Autonomy Throughout History ................................................. 8

Definition of Autonomy............................................................ 9

Erickson's Autonomy versus Shame and Doubt......................... 9

Autonomy and Occupational Therapy...................................... 10

Collopy's Six Polarities on Autonomy......................................... 11

Autonomy and Daily Activities............................................... 13

Autonomy and Disability ..................................................... 14

Disability

Disability in the United States and the ADA ............................... 15

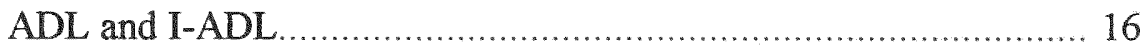

Driving Disability Categories.................................................. 17

Spinal Cord Injuries

Spinal Cord Injury in the United States................................... 18

Spinal Cord Injury Prognosis................................................. 18

Acceptance and Compliance to Spinal Cord Injury ....................... 19

Social Support and Spinal Cord Injury ...................................... 20

Employment and Spinal Cord Injury........................................ 21

Vocational Readjustment and Spinal Cord Injury ........................ 22

Driving

Spinal Cord Injury and Driving................................................ 23

Elderly Drivers..................................................................... 23

Physical and Cognitive Changes That May Affect Elderly Drivers.. 24

The Elderly and Driving Rehabilitation Programs......................... 25

Driving Rehabilitation Program Referrals ................................... 27

Occupational Therapists as Driving Evaluators........................... 27

Driving Assessments............................................................. 28

Ethical Issues Facing Driving Evaluators...................................... 31

Problems Found in Driving Evaluations ......................................... 31

Driving Simulators.................................................................. 32

History of Automotive Adaptive Equipment for Disabled Drivers... 35

Car Manufacturers and Disabled Drivers..................................... 35

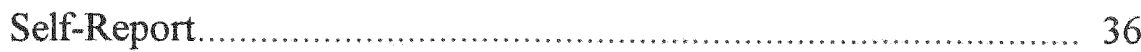

Model of Human Occupation......................................................... 37 
III. METHODOLOGY ................................................................ 41

Objective and Research Questions......................................... 41

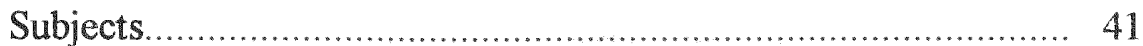

Data Collection.................................................................... 42

Statistical Analysis................................................................... 43

Limitations of the Study ........................................................ 44

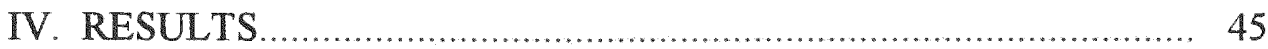

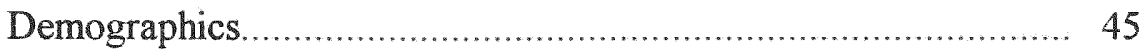

Descriptive Statistics............................................................. 49

Frequencies and Percentages of Survey Responses..................... 49

Relevance of Driving............................................................. 54

Autonomy, Driving and Daily Activities.................................... 54

Autonomy and Driving ......................................................... 55

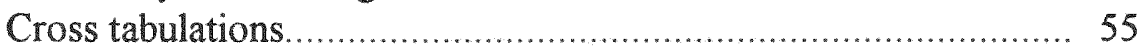

Statistical Analysis................................................................ 56

Differences by Level of Spinal Cord Lesions and Autonomy......... 56

Demographic Differences Between Subjects............................... 61

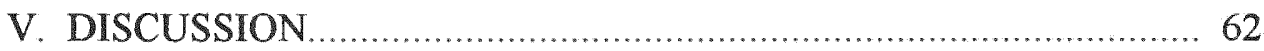

Characteristics of Subjects...................................................... 62

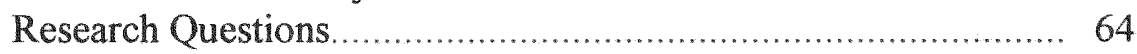

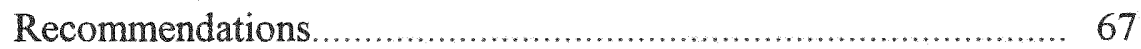

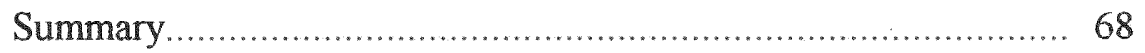

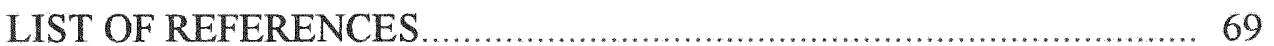

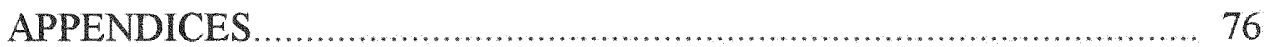




\section{LIST OF TABLES}

TABLE

1. Frequencies and Percentages of Demographic Data of Subjects.................... 46

2. Frequencies and Percentages of Demographic Data of Subjects.................... 50

3. Frequencies and Percentages of Responses to Survey Questions.................... 51

4. Frequencies and Percentages of Responses to Survey Questions..................... 53

5. Differences Among Subjects in Driving Behaviors ....................................... 57

6. Driving Differences After Participating in a Driving Rehabilitation Program...... 58

7. Significant Differences Between Subjects by Spinal Cord Lesion and Autonomy. 59

8. Means and Standard Deviations of Spinal Cord Lesion Levels and Autonomy.... 60 


\section{Chapter I}

\section{Introduction}

Driving is often viewed as a privilege within American culture and a necessity in certain geographical areas. In the state of Florida the importance of being able to drive a vehicle is evident. Out of 5,794,452 individuals, $77.1 \%$ drove alone, $14.1 \%$ car pooled with others, $2.0 \%$ used public transportation, and $6.8 \%$ used other forms of transportation (U.S. Census Bureau, 1990). Each day thousands of individuals get into their vehicles allowing them to independently go to work, to school, and to other needed places. They give little thought to these seemingly simple tasks, but for many this is not such an easy and automatic process. When one envisions an adult, someone who is independent in all aspects of their lives comes to mind. However, one's independence may be compromised due to trauma such as a spinal cord injury, among other factors. Independence through mobility remains important to an individual, whether they have had a recent spinal cord injury or one that occurred several years ago (Sprigle, Morris, Nowachek, \& Karg, 1995).

When a spinal cord injury occurs, feelings of helplessness and loss of control are often experienced and carry over to other aspects of one's life. A negative self-concept and loss of autonomy have been shown to cause a decline in health and overall survival rate among segments of the population (Kiernat, 1987). For many individuals having a driver's license is greatly valued, with or without a disability. Driving is believed to be an essential daily activity, which allows for the accomplishment of several goals. Lillie (1993) found that some drivers preferred not to live than never to be able to drive again. Thus, feeling in control of one's life is vital and tied to one's life satisfaction, and in particular to feelings of autonomy. Murphy, an author with disabilities believes that 
mastering his environment and maintaining a sense of autonomy was directly related to his overall life satisfaction (Murphy, 1990).

Occupational therapy plays a vital role in rehabilitating individuals with spinal cord injuries. "Its fundamental concern is the development and maintenance of the capacity throughout the life span, to perform with satisfaction to self and others, those tasks and roles essential to productive living and to the mastery of self and environment" (Pedretti, 1996, p.6). Occupational therapists are specialized in assessing performance, activities of daily living, providing treatment objectives, education, training, and the use of needed equipment to achieve and enhance independence. Those who lose the capacity to manage their personal needs show lower self-esteem, due to their inability to carry out their everyday tasks. This puts a greater burden on their relationships with others. Individuals with spinal cord injuries place a great emphasis on being able to perform activities of daily living as independently as possible (Malick \& Almasy, 1983).

Driving is a daily activity that is considered to be a complex task, because it requires individuals to be able to correctly process and integrate information from their environment. It carries a greater risk factor in terms of safety, in comparison to other activities of daily living. Driving rehabilitation evaluators, who are usually physiatrists, occupational therapists, and neuropsychologists, are trained individuals who specialize in the area of driving (Galski, Ehle, \& Williams, 1997).

An individual who is referred to a driving program, due to a spinal cord injury, undergoes a thorough assessment to determine their ability to resume or drive for the first time. A driving evaluation determines the specific vehicle that is most appropriate for an individual, and whether any adaptive equipment or further training will be needed. Final 
recommendations are made by the rehabilitation team. Based on their professional opinions and the results of the evaluation, they identify who is capable of being a safe driver. This is done to protect the rights of the individual going through the driving rehabilitation program, as well as all members of society (Galski, et al. 1997). Significance of the Study

This study is significant to all individuals with disabilities because it examined how through driving, one's autonomy can be maintained or enhanced. Individuals with disabilities may learn from this study about how other individuals similar to themselves, have been able to independently drive to perform daily activities. This study may expose individuals to the possibilities of driving with disabilities, that they other wise may not have known about. This study is also significant because it has added knowledge to the areas of autonomy, spinal cord injury, and driving, which have been greatly lacking.

\section{Statement of the Problem}

The problem is that there is a lack of research in the areas of autonomy, spinal cord injury, and driving. The majority of literature on autonomy has focused on informed consent, family caregiving and the elderly. There is a lack of research in regards to autonomy among individuals with spinal cord injuries and other forms of disabilities. However, researchers such as West, Hock, Wittig, and Dowdy (1998), believe that there is a link between autonomy and mobility through transportation among individuals with disabilities. Being able to independently go to desired places, provides individuals with more options in their life. This can include employment and a variety of other activities.

The majority of the spinal cord injury literature has focused on physical rehabilitation and the potential for functional gains. Most of the studies conducted were 
done within a short time frame since the spinal cord injury, showing a need for more longitudinal studies. Of particular importance was that little attention was given to how psychosocial aspects, such as autonomy influence recovery.

Driving rehabilitation programs vary greatly in the evaluation methods used. However, evaluations generally consist of a prescreening or off-road evaluation to determine visual, perceptual, cognitive, and physical functioning, and a behind-the wheel or on-road evaluation. According to Galski et al. (1997), some programs use a driving simulator in conjunction with the off-road and on-road evaluations. Although the driving evaluations used may differ among facilities, they are consistent in showing a lack of evaluating how one's autonomy is affected by being able to drive again or for the first time after a spinal cord injury. There are few studies that actually measure how the individual's feelings of life satisfaction, in particular to how the level of autonomy has been affected, due to a driving rehabilitation program. For many individuals with spinal cord injuries, the training and recommendations received from driving evaluators will allow them to have a greater sense of autonomy by being able to drive. Yet, there is a great lack of research being conducted to validate this (Breske, 1994).

A study conducted by Jones, Giddens, and Croft (1983), can serve as a model for driving rehabilitation programs. They conducted a follow-up study on 300 individuals who went through a driving program. The results showed that driving was perceived by these individuals as being extremely important and was related to their quality of life. This is one of the few studies that has determined the effects and benefits that a driving rehabilitation program can offer. 


\section{Objective and Research Questions}

The objective of this study was to examine how autonomy is affected among individuals with spinal cord injuries by being able to drive again or for the first time, through participating in a driving rehabilitation program.

Five research questions were addressed in this study:

1. What level of autonomy do individuals with spinal cord injuries who have gone through a driving rehabilitation program experience?

2. Do individuals with spinal cord injuries who have gone through a driving rehabilitation program experience a sense of improved autonomy in their life?

3. Is there a difference in the amount of time individuals spent driving before their injury, disability, or condition to after their injury, disability, or condition and going through a driving rehabilitation program?

4. Is there a difference in driving-related autonomy of individuals by level of spinal cord lesion after going through a driving rehabilitation program?

5. Are there differences in driving-related autonomy of individuals with spinal cord injuries by age, marital status, gender, education, ethnicity, and employment status after going through a driving rehabilitation program?

\section{Definitions}

Autonomy - The natural right of rational human beings to be self-determining by making their own decisions. Individual's choices should be respected by others, since they are the ideal person to know what is in their best interest (Bailey \& Schwartzberg, 1995). Americans with Disabilities Act (ADA) - Does not allow for the discrimination of individuals in the area of employment to those who are qualified for a job position and 
considered to be disabled. This may include reasonable accommodations to fit each individual's specific employment needs. The ADA also ensures accessibility to services provided at the state and local government level to those with disabilities (Pedretti, 1996). Disability - "Refers to any restriction or lack of ability to perform an activity in the manner or within the range considered normal" (World Health Organization, 1980). Handicap - "Represents a disadvantage experienced by an individual as a result of an impairment and disability "that limit or prevent fulfillment of a role that is normal (depending on age, sex, and social and cultural factors) for that individual" (World Health Organization, 1980).

Impairment - "A loss, abnormality, or disturbance of an anatomical, physiological, mental, or emotional structure or function that may be temporary or permanent" (World Health Organization, 1980).

Activities of Daily Living - These activities require basic skills and consist of mobility, self-care, and communication categories (Pedretti, 1996).

Instrumental Activities of Daily Living - These activities require higher skills and consist of home management, community living skills, and health and safety management (Pedretti, 1996).

Self-Report - Data collected from a subject's own view about themselves; considered to be the opposite of objective data collected by an observer who is impartial (Meltzoff, 1998).

\section{Assumptions}

The following assumptions were relevant to this study:

1. Driving is an activity that is valued by some individuals who have sustained a spinal 
cord injury.

2. The principle of autonomy exists and is important to individuals to maintain throughout the life span.

3. The participants in the study will answer the questions on the survey to the best of their abilities. 


\section{Chapter II}

\section{Literature Review}

\section{Autonomy Throughout History}

Autonomy was first described by Greek philosophers and was defined as, "autos nomos" or "self-rule" (May, 1998). The writings of Aristotle show how he used the term autarkeia in a political sense to mean self-sufficiency, a primary goal for a city and state to achieve. He also referred to autarkeia as the ability of man to reason. Kant was influenced by Aristotle's autarkeia and believed that autonomy was part of a natural developmental process for human beings. He believed that man had the ability to use reason and must do so to make decisions that satisfy their own personal goals and needs (Cicirelli, 1992).

Throughout American history the concept of independence has played an integral part in our society. Americans have always valued freedom and autonomy as two of the most important aspects of life. This is evidenced by the founding fathers writings of the Declaration of Independence, the Bill of Rights, and the Constitution. Among America's most cherished ideals are "life, liberty and the pursuit of happiness", as was stated in The Declaration of Independence in 1776 (Glasser \& Adelman, 1991). Americans consider those concepts as being intrinsically natural rights. They have fought in numerous wars to secure the freedom of its citizens. Each year the United States celebrates Independence Day on the fourth of July as a national holiday, signifying the victory over the many struggles that were encountered to maintain their country's independence (Glasser \& Adelman). 


\section{Definition of Autonomy}

Autonomy is a concept that has often been used interchangeably with other terms.

The Merriam-Webster's Collegiate Dictionary defines autonomy as "the quality or state of being self governing; self-directed freedom and especially moral independence" (MerriamWebster's Collegiate Dictionary, 1998, p. 79). Therefore, autonomy often becomes difficult to define and researchers have called for a more precise definition. Although autonomy means, "self-rule" there are outside constraints to one's level of autonomy. This can include the environment, rules and mental and physical impairments, among other factors. A truly autonomous person recognizes that they have the right to direct their own lives, as long as they do not harm others and act accordingly within the rules of society (Horowitz, Silverstone, \& Reinhardt, 1991). Research has shown that autonomy is most often used as an ethical concept in a variety of settings and contexts. In the medical field autonomy has been used to describe informed consent, patient competency, animal testing and abortion, among other issues. Within the legal field, it has been used to describe privacy and constitutional rights. The business industry has used autonomy to describe advertisers and consumer rights (May, 1998).

Erickson's Autonomy versus Shame and Doubt

Within American society autonomy has always been valued and respected as a goal to be attained. Beginning at an early age parents support their children in being as independent as possible. Milestones such as a baby's taking their first step and saying their first word are often celebrated, encouraging their child in becoming an autonomous being. Erickson described eight psychosocial stages that individuals go through over a life span. These include trust versus mistrust, autonomy versus shame and doubt, initiative 
versus guilt, industry versus inferiority, identity versus identity diffusion, intimacy versus isolation, generativity versus stagnation, and integrity versus despair. The second stage pertains to autonomy versus shame and doubt. A child learns in their second and third year of life to achieve a balance between being autonomous while respecting societal needs. The goal of this stage is for the child to recognize that they are a separate being capable of self-regulation, in which will power will be fostered. When this does not occur, the child experiences shame and doubt and lets one's impulses control their behavior (Goleman, 1988).

\section{Autonomy and Occupational Therapy}

Within the field of occupational therapy autonomy is a concept that is directly addressed in the Occupational Therapy Code of Ethics. Principle number two states that, "Occupational therapy personnel shall respect the rights of the recipients of their services (e.g., autonomy, privacy, confidentiality)" (The American Occupational Therapy Association, 1996, p.632). Occupational therapists respect their client's autonomy on an ongoing basis throughout treatment. This can include a variety of factors, such as collaborating on goals for treatment with a patient, educating patients on the risks and benefits of a treatment procedure, and maintaining confidentiality. Occupational therapy intervention focuses on functional independence within performance areas and components, while taking into account the environment, social and cultural issues. Respecting patient autonomy needs to be considered in order to truly increase their independence not only in a functional, but a more global sense as well (Kiernat, 1987). 


\section{Collopy's Six Polarities on Autonomy}

According to Horowitz et al. (1991), Collopy is considered to be a leading researcher in autonomy. He conceptualized six polarities for autonomy and specifically tied them to long term care centers. However, these concepts have been applied to a variety of settings. The first polarity is decisional versus executional autonomy. Decisional autonomy is when a person has the freedom to make decisions without being coerced. Executional autonomy is when a person can implement their own choices (Collopy, 1988). Many individuals may not be able to physically execute an act because they may be limited due to a physical impairment. Under these circumstances decisional autonomy can be maintained by directing another on how to execute their goals. Research has shown that individuals who can not physically control aspects of their environment, need to at least feel a perception of control. According to Ryden (1984), even if the decisions made were minimal, they made a large difference in their levels of competency and autonomy. The restoration of feelings of confidence in their decision making abilities was evidenced. It may be time consuming for health practitioners to allow individuals to make daily choices. However, in the long run it will increase their level of autonomy, which should be the primary goal for every health care professional (Kiernat, 1987).

The second polarity is direct versus delegated autonomy. Direct autonomy is when an individual is independent in making decisions. Delegated autonomy is when an individual willingly allows others to make decisions for them. Collopy (1988) cautions against using delegated autonomy because this may hinder an individual's autonomy in any setting and fosters dependency on others.

The third polarity is competent versus incapacitated autonomy. Competent 
autonomy is when reasonable and coherent decisions are made. Incapacitated autonomy is when unreasonable and incoherent decisions are made. However, this issue can become controversial because what one person may consider to be an appropriate and coherent decision, may be viewed as incorrect by another. If an individual is suspected of being incompetent in their decision making capacities, interventions in altering their decisions are brought into question. Benevolent paternalism was created to protect patients against harmful decision making on their part. It states that it is ethical for health practitioners to disregard a patient's decisions, if they are believed to be incompetent and their choices puts them or others at risk (Collopy, 1988). Researchers caution practitioners when using benevolent paternalism because it can not be justified if a patient is considered to be competent and there must be evidence to prove that the patient is incompetent. When this occurs health practitioners are caught in a dilemma of respecting their patient's autonomy, while at the same time adhering to the principle of beneficence, which obligates them to act for the good of the patient. The issue of when to decide that someone has made an incapacitated autonomous decision that requires nullification, remains unclear and debatable (Coy, 1989).

The fourth polarity is authentic versus inauthentic autonomy. Authentic autonomy means that an individual's decisions are in accordance with their overall character. Inauthentic autonomy means that an individual's decisions are not in accordance with their personality. A problem may arise when an individual decides to act by free will in a way that is different from how they may have acted in the past. Caregivers may view the individual as being inauthentic, when in fact they have just simply decided to act autonomously and change their mind (Collopy, 1988). 
The fifth polarity is immediate versus long range autonomy. Immediate autonomy is a person's freedom to make autonomous decisions in relation to a present and specific issue. Long range autonomy is a person's freedom to make autonomous decisions in relation to a future and non-specific issue. Collopy recognizes that paternalistic involvement may be necessary if an individual is presently acting in a way that will hinder their future level of autonomy. In such cases intervention may be warranted to preserve their level of autonomy in the future (Collopy, 1988).

The sixth polarity is negative versus positive autonomy, which are built on the philosophical concepts of individual rights. Negative autonomy is when an individual is free from coercion in their decisions. Positive autonomy is when others offer support and resources to an individual that needs assistance, in order for that person to achieve true autonomy. Collopy cautions that both forms of autonomy can have negative consequences. Social isolation can result from non-interference for populations that need help, if negative autonomy is adhered to. Too much dependence may be fostered when using positive autonomy (Collopy, 1988).

Autonomy and Daily Activities

Many individuals due to severe circumstances are unable to care for themselves and become dependent on others for their basic survival, in which case autonomy becomes jeopardized. This is particularly evident in long term care centers, such as nursing homes. In a study conducted by the National Citizens Coalition for Nursing Home Reform, 457 residents from different nursing home facilities were angered by their lack of input in making daily decisions for themselves (Kiernat, 1987). Research has shown the importance of being able to exert control over one's environment, to prevent feeling 
helpless. When an individual is able to control their environment their performance level has been shown to increase. To prove this, Langer and Rodin conducted a study in 1976. They divided nursing home residents into two groups. The first group was given a lecture on how they had responsibility and control over their daily activities. They were allowed to choose a plant to care for directly. The second group was told that the staff was responsible for their care and daily activities. A plant was given to each resident, which a staff member cared for instead of the resident. The results showed that the first group who directly cared for the plant, were happier and in better health in comparison to the second group who did not have any direct care for the plant. The study illustrates the relevance of allowing individuals to have autonomous input over their daily activities (Langer \& Rodin). Research has also found that it is important to evaluate what a patient can do in order to distinguish what responsibilities they can perform, instead of focusing on what a patient can not do for thernselves (Jameton, 1988).

\section{Autonomy and Disability}

A study conducted by Decker and Schulz (1985) investigated individuals with spinal cord injuries over a five year period. They found that perception of control over one's life was the best predictor of autonomy and their overall satisfaction with themselves. The participants in their study reported a level of life satisfaction that was minimally lower in comparison with people who did not have any disabilities. The majority of these subjects believed that they could still lead a fulfilling life, despite their spinal cord injury.

In the Netherlands, the government provides free adaptations within the homes and vehicles of individuals with spinal cord injuries. Individuals felt that having a vehicle with 
adaptations was related to being autonomous, because driving allowed them to take care of their necessities. Drewes conducted a study and found that $81 \%$ of individuals with paraplegia and $78 \%$ of individuals with tetraplegia were able to drive due to ownership of adapted vehicles, in the Netherlands. This is in contrast to the 2.5 million Americans who reported that they needed adaptive equipment for their vehicles, but could not afford them (Post, Asbeck, Dijk \& Schrijvers, 1997).

Another study which examined autonomy and disability was conducted by Murtaugh and Zetlin (1990), investigated 30 learning handicapped and nonhandicapped adolescents. They found that the parents of handicapped adolescents had a more difficult time allowing their children to achieve autonomy in comparison to the parents of nonhandicapped adolescents. This was attributed to the fact that the parents of the handicapped adolescents had already encountered several behavioral set backs with their children. Adolescents with handicaps were more eager to achieve autonomy in comparison to their nonhandicapped counterpart. It was believed that nonhandicapped adolescents probably desired less autonomy because they were already some what content with the level of autonomy they were given. Parents with handicapped adolescents who had the least problems in giving their child more independence, introduced autonomy at the beginning of their development and at a more consistent pace throughout the years (Murtaugh \& Zetlin).

Disability in the United States and the Americans With Disabilities Act

Within the United States there are 43 million Americans with physical and mental disabilities, and this population increased by $400 \%$ from 1965 to 1990 . The majority of these individuals were employed prior to becoming disabled, however very few will 
actually return to the work force, although many desire to do so. Studies indicate that $67 \%$ of those with disabilities are unemployed due to several factors. These include discrimination due to their disability and unaccessible means to private and public transportation, among others. These obstacles need to be eliminated, since rehabilitating and educating those with disabilities is considered to be everyone's advantage (International Center for the Disabled, 1986).

On July 26, 1990, the Americans with Disabilities Act (ADA) was passed, ensuring that all individuals with disabilities are given an equal opportunity in employment, public accommodations, state and local government services offered, telecommunications, and transportation. State and local government services became accessible to those with disabilities, either through the removal of architectural barriers present or by altering company policies. The ADA has helped to alleviate many problems and discriminations that individuals with disabilities experienced (Bachelder \& Hilton, 1994).

Although several advances have been made, those with disabilities still face many obstacles. A study conducted by Burnett and Yerxa (1980), found that the disabled in comparison to the non-disabled population showed lower self-confidence in performing several skills. These included activities of daily living in the social, recreational, vocational, and mobility areas. These findings show that those with disabilities have several needs which are still not being met. Burnett and Yerxa believe that a greater emphasis should be placed on helping them to achieve more appropriate daily living skills in order for them to live independently within the community.

\section{Activities of Daily Living and Instrumental Activities of Daily Living}

Activities of daily living (ADL) and instrumental activities of daily living (I-ADL) 
are an important aspect of an individual's life. ADL consist of self-care tasks, mobility and communication skills. I-ADL are considered to be more complex skills and consist of home management, health management, safety management and community living skills. Driving is considered to be an I-ADL. For those with disabilities, ADL and I-ADL become more challenging tasks to accomplish, in which rehabilitation programs have been developed to further enhance their quality of life (Malick, et al. 1988).

\section{Driving Disability Categories}

Driving can increase the number of opportunities that allow an individual to participate in selected activities, whether they are recreational in nature, such as playing tennis or of necessity, such as grocery shopping. When an individual experiences an injury, disease or other form of trauma disrupting their lives, vital links to their outside world may be cut. Several programs have been implemented to allow individuals with disabilities to drive. Drivers with disabilities are categorized into three levels, those who are physically disabled, those with cognitive disabilities, and those with a combination of the two. The literature reports that those with physical disabilities will require training in the use of adaptive equipment and those with cognitive disabilities need to be trained in compensatory techniques. It is usually a longer process to train the cognitively disabled in comparison to the physically disabled (Sprigle, et al. 1995).

A review of the literature indicates that there is not one specific diagnosis that has been identified among drivers with disabilities, but rather individuals with a variety of disabilities have been reviewed. These include the elderly, head injuries, cerebrovascular accidents, spinal cord injuries, amputations, cerebral palsy, multiple sclerosis, muscular dystrophy, and poliomyelitis, among others. However, the majority of the literature has 
examined those with spinal cord injuries, head injuries, and cerebrovascular accidents. Specific problems unique to each disability will vary among individuals (Breske, 1994).

\section{Spinal Cord Injury in the United States}

There are approximately 207,000 individuals with spinal cord injuries in the United States. It is estimated that 10,000 spinal cord injuries occur each year. Approximately a total of $\$ 7,736$ billion dollars are being spent on this population. On a yearly basis, $35.9 \%$ of all spinal cord injuries are due to vehicular accidents. Approximately $29.5 \%$ are due to violent acts, such as gun shot wounds, $20.3 \%$ are due to falls, $7.3 \%$ are due to injuries incurred during sports activities, and 7\% are due to other causes (DeVivo, 1997). Spinal cord injuries occur more frequently among younger male individuals, in comparison to other demographic groups (Frankel, Coll, Charlifue, Whiteneck, Gardner, Jamous, Krishnan, Nuseibeh, Savic, \& Sett, 1998). Within the next decade the overall incidence of spinal cord injuries is expected to increase by $20 \%$ (Lasfargues, Custis, Morrone, Carswell, \& Nguyen, 1995).

\section{Spinal Cord Injury Prognosis}

The life expectancy and survival rate of individuals with spinal cord injuries has increased significantly within the last 40 years (Frank, Valin, \& Elliott, 1987). Paraplegia or quadriplegia are the results of a spinal cord injury. Paraplegia is paralysis of the lower extremities and may involve part of the trunk. Quadriplegia is paralysis of both the upper and lower extremities, in which upper extremity use may be preserved depending on the level of the lesion to the spinal cord. Spinal cord injuries can occur to the cervical, thoracic, and lumbar region. The higher the lesion in the spinal cord, the worse the prognosis is. Prognosis after a spinal cord injury is dependent upon whether there is a 
complete or an incomplete lesion. For a complete lesion, the prognosis is poor if there is no sensory or motor return below the level of lesion within the first to second day after the injury. However, part or full recovery below the level of lesion may occur within the first six months after the injury (Wilson \& McKenzie, 1984). Research shows that there is an increase in incomplete and less devastating spinal cord injuries. This is due to several advances in medical technology, which allow for faster responses to occur during the initial phase of a spinal cord injury. Overall, it has been indicated that individuals with incomplete spinal cord injuries experience a greater functional outcome than those with a complete spinal cord injury. They achieve a higher level of independence and are hospitalized for shorter time periods (Gerhart, Johnson, \& Whiteneck, 1992).

\section{Acceptance and Adjustment to Spinal Cord Injury}

For the past 50 years, researchers have been examining how individuals with spinal cord injuries accept their condition. Research has shown that individuals who have difficulties accepting their condition showed a decrease in quality of life and had poor activities of daily living skills. Individuals who were hopeful and believed that they had a potential for recovery, accepted their condition more often than those individuals who were not positive. They also showed better adjustment patterns and higher emotional functioning. Researchers agree that compliance and acceptance of a spinal cord injury is dependent on the individual's past coping strategies and individual personality traits. There is no definite way for clinicians to identify which patients will accept their condition in a favorable or unfavorable manner (Cairns \& Baker, 1993).

In the 1950 's researchers reported that they wanted to learn more about the psychological effects of spinal cord injury on an individual. Since then, researchers began 
to investigate psychological reactions that individuals with spinal cord injuries experience. These included stages of grieving similar to those delineated by Kubler-Ross, in which depression, anger, dependency, and other reactions were noted. Several authors have proposed their own theories of psychological responses among those with spinal cord injuries. However, a clear consensus on the exact reactions and sequence experienced has not yet been achieved. Researchers have concluded that each individual with a spinal cord injury is unique and will experience different emotions (Frank, et al. 1987).

Researchers in the past believed that depression was a natural response to a spinal cord injury because significant abilities were compromised or lost. However, these views have changed. A study conducted by Dew, Lynch, Ernst, and Rosenthal (1983), found a mean score of $9.74 \%$ for depression among 111 spinal cord injured patients. This was found to be comparable with the mean score for depression within the general population. A longer rehabilitation process and poor adjustment to spinal cord injury has been found among those individuals diagnosed with depression. Other findings suggest that the suicide rate among the spinal cord injury population is twice as high in comparison to the general population (Cairns \& Baker, 1993).

\section{Social Support and Spinal Cord Injury}

Social support has been noted as being extremely important in the adjustment and recovery process, among those who have suffered a spinal cord injury. Support from others has been found to allow individuals to better cope with their disability and have a higher self-image of themselves. Within the last 30 years there has been an increase in the number of studies being conducted on the influence that social support has on an individual with a disability. Family members have become increasingly involved in the 
rehabilitation process of individuals with physical injuries (Decker \& Schulz, 1985).

Social support has been found to be a strong predictor of how an individual with a disability or illness adjusts to their condition and rehabilitation process. Research has shown that the amount of support received has a direct influence on a patient's recovery and adjustment. A study conducted by DiMatteo and DiNicola (1982), found that when support was given, patients tended to follow rehabilitation treatment protocols at a higher level than those who did not receive this support. In particular social support seems to offer a patient the opportunity to communicate and problem solve with a loved one, lowering the amount of stress experienced.

It has been found that for individuals who are married to someone with a spinal cord injury, early involvement in their spouse's rehabilitation process seemed to allow both parties to better adjust to the disability. For the wife, supportive resources were the most important factor for her adjustment. Patients with supportive families and friends tended to return to work at a higher rate because they felt more confident. The majority of the literature has focused on how a disability affects the person who has experienced an injury (Kelley \& Lambert; 1992).

\section{Employment and Spinal Cord Injury}

Returning to work has been considered to be one of the most important rehabilitation goals for those who have sustained a physical injury to achieve. However, disabilities can profoundly affect and complicate the ability to return to previous or first time employment. A spinal cord injury can have devastating and permanent effects, making employment difficult or unattainable (Krause, 1996). Several roles the individual had previously been comfortable in performing become jeopardized and difficult to 
resume, due to physical and psychosocial complications from a spinal cord injury. A national study was conducted on approximately 16,000 individuals with spinal cord injuries. It was estimated that out of $61 \%$ of individuals who were employed prior to their injury, only $14 \%$ resumed employment one year after their injury. Five years later, only $24 \%$ had returned to work (Krause \& Anson, 1997).

Employment rates vary considerably among those with spinal cord injuries and appears to be related to a number of factors. A positive correlation has been found among individuals with spinal cord injuries with more years of education and a higher employment rate. A study conducted by Krause in 1992, found that individuals with spinal cord injuries with 16 years or more of education had an employment rate of $70 \%$. Those who had less than 12 years of education had an employment rate of $3 \%$. Individuals with spinal cord injuries who were employed reported to be better adapted to their life, were more active, and had less financial problems than those who were not employed (Krause, 1996).

\section{Vocational Readjustment and Spinal Cord Injury}

The majority of individuals with spinal cord injuries do not reenter the work force immediately after their injury. There is a time period in which adjustment to their condition often takes place. It is estimated among vocational counselors working with individuals with spinal cord injuries, that they will take approximately $2-5$ years to reach a true potential to return to work. Vocational pursuit was the lowest around the first 2 years after the initial spinal cord injury occurred. Individuals who sought vocational counseling returned to work at a higher rate than those who did not. They were either in school or working three years after their injury. Due to the high costs of living with a 
spinal cord injury, many individuals often fear returning to work because they do not have the skills or education to maintain a stable and well paying job. They are also reluctant because they may be receiving higher unemployment checks than what their actual salary at a job would be (Crisp, 1990).

\section{Spinal Cord Injury and Driving}

Marlon Brando's acting debut in the movie, "The Men", depicts the importance of transportation and autonomy to individuals with spinal cord injuries (Koppa, 1990). A review of the literature indicates that there is lack of research concerning how one's level of autonomy is improved by being able to drive after a spinal cord injury. The literature has focused on the driving capabilities of those with spinal cord injuries according to the level of their lesion. Individuals with a $\mathrm{C} 5$ to a T9 lesion may be able to drive an adapted van. Those with a T10 to L2 may drive with the use hand controls, and individuals with an L3 to S3 lesion may drive a vehicle without any modifications (Pedretti, 1996).

\section{Elderly Drivers}

In the last two decades there has been an increase in the number of older drivers. The elderly are considered to be the fastest growing age group of drivers in the United States. It is estimated that 1 out of 4 drivers will be over the age of 65 by the year 2024 (Park \& Smith, 1991). Elderly drivers represent $7.6 \%$ of all drivers with licenses, yet $48 \%$ of them are involved in vehicular accidents (Cox, Fox, \& Irwin, 1989). Among all age groups, the elderly have the highest number of traffic convictions and are second to those under age 20 for reported vehicular accidents. More fatalities occur among the elderly from vehicular accidents and they sustain more severe injuries in comparison to their younger counterparts (Hutcherson, 1989). 
Reviewing a client's driving history can help identify unsafe driving habits. The most common difficulties that the elderly population experience when driving include night driving, poor adjustment to speed changes, getting lost, failing to exit highways properly, improper lane changing, and difficulty reading and interpreting traffic signs. Modifications can be made to help increase the safety level of elderly drivers, which need to be based on their individual needs. This may include a restriction in the individual's driving routine, such as driving during the day and avoiding rush hour (Carr, 1993). Research has been conducted to determine any changes that can be made to highways to make driving safer for the elderly. This includes several factors, such as an examination of the amount of lighting available at night. It appears that modifications can be made when possible to the elderly individual's driving behaviors. Researchers believe that society as well needs to take responsibility in making adjustments to the driving environment, to secure elderly driver's level of autonomy (Schieber, 1994).

\section{Physical and Cognitive Changes That May Affect Elderly Drivers}

The elderly may experience cognitive and physical changes that can affect their ability to drive safely, placing themselves and the public at risk. As an individual ages they may experience a decrease in static visual acuity and pathological occurrences in the eye, such as macular degeneration and cataracts. The pupil of the eye becomes smaller requiring more light for the lens to focus, producing a glare. There is a decrease in peripheral vision and in the ability to distinguish among colors (Hutcherson, 1989). These factors may all have a profound effect on one's visual and perceptual ability to drive. Visual deficits have been found to be related to vehicular accidents among the elderly (Park \& Smith, 1991). 
It is estimated that $30 \%$ of the elderly have some hearing impairments which may interfere with their ability to distinguish sounds while driving (Hutcherson, 1989). The ability to correctly distinguish noises within the environment is extremely important when driving, such as being able to hear ambulances, law enforcement vehicles, and other emergency situations. There is a lack of research available on how hearing loss affects the elderly driver in relation to vehicular accidents (Carr, 1993).

Chronic cognitive conditions, such as dementia can severely affect one's ability to drive and may put the driver and the public at great risk. Cognitive assessments usually include safety judgment, attention span, analytical processing, planning and decision making, and selected and divided attention (Hutcherson, 1989). Other factors that can affect cognitive abilities include medication and alcohol consumption. In general, older drivers take medications more readily than younger individuals, which can affect their driving abilities. Although research shows fewer cases of vehicular accidents due to alcohol use within the elderly, an increase in alcoholism has been noted among this population in recent years. To properly assess one's overall cognitive status, it may be important to examine the medication that a client is taking and to check for alcohol use.

Musculoskeletal deformities can also occur with age to the spine and neck, among other areas limiting one's range of motion. This can have a profound effect on a driver's ability to sufficiently move their body while driving, affecting their overall visual-perceptual skills (Carr, 1993).

The Elderly and Driving Rehabilitation Programs

Attention to driving rehabilitation programs geared towards elderly drivers specific needs has received recent attention. The National Highway and Traffic Safety 
Administration (NHTSA) provided funding to General Motors (GM) to conduct research on determining the factors that would enable elderly individuals to drive in safer ways. John Eberhard, a research psychologist for NHTSA believes that this is beneficial to the elderly and society. He believes that occupational therapists are qualified in enhancing driving skills among the elderly. This is supported by the fact that $75 \%$ of the members from the Association of Driver Educators for the Disabled (ADED), are occupational therapists (Berg, 1998).

Linda Hunt is an occupational therapist who is a driving rehabilitation instructor with an elderly clientele. She has examined how elderly drivers who have physical impairments, but are cognitively intact can be trained to drive safely. Individuals receive six hours of behind-the-wheel training, and are given clinical evaluations examining physical and psychological components. GM pays for any necessary modifications to the vehicle, allowing for the elderly individual to drive. Few programs similar to this one exist and motor vehicle departments are reducing funding that could help elderly drivers (Berg, 1998). The majority of states do not enforce strict guidelines for license renewal, which can be done by mail with a small fee. In some states more rigid policies are followed for renewing the licenses of individuals over the age of 70 . However, few periodic assessments of driving capabilities are done, especially to the elder population who may not be able to drive in the same manner they did a few years ago (Gillins, 1990).

There is a need for more effective screening tools that will identify safe and unsafe drivers to protect all individuals on and off the road. Driving rehabilitation programs designed to help address the specific needs of the elderly population need to be implemented in each state to facilitate elderly persons independence. Transportation 
resources also need to become more readily available for those whom driving is no longer an option (Berg, 1998).

\section{Driving Rehabilitation Program Referrals}

Several health care professionals can refer a patient to a driving program; physicians, therapists, nurses, and social workers are the most common ones. In general the physician is primarily responsible for deciding when an individual is capable of driving after a disability. Referrals are made based on several factors, such as when a patient is diagnosed with a neurologic disorder and disease, exhibits visual deficits, and displays neuromuscular weakness. A health care member or caregiver may express their concern about an individual's abilities and their capacity to drive safely. The main purpose of a referral is to facilitate the individual to drive independently. All disabled drivers will not be able to go through a driving rehabilitation program, because they cannot afford them and insurance companies usually do not cover their cost (Sprigle, et al. 1995).

\section{Occupational Therapists as Driving Evaluators}

It is estimated that $62 \%$ of all evaluators in rehabilitation driving programs are occupational therapists. Research has shown a need to ensure that occupational therapists working in driving rehabilitation programs become highly trained in appropriate driving skills. They are trained and qualified in a variety of areas that are addressed in driving rehabilitation programs. This includes training in visual-perceptual skills, cognition, functional mobility, transfers and the use of adaptive devices, among other areas. They also consider each individual as being unique, with their own values, interests and goals. Each disabled driver will have different needs that may be met through the expertise of a driving rehabilitation specialist, such as an occupational therapist (Sprigle, et al. 1995). 


\section{Driving Assessments}

The goal of a driving evaluation is to thoroughly assess an individual's ability to drive. Adaptive devices, the correct vehicle, and the specific amount of training needed are determined on an individual basis throughout the driving evaluation. Evaluations vary greatly among facilities. They usually consist of a clinical, stationary, and driving evaluation. The clinical or predriving assessment, begins with the review of the individual's medical records. This will determine any medical conditions that the driving evaluator needs to be aware of. An individual may not be fit to drive, depending on the state they live in if they are prone to seizures and have cardiac problems. They may lose consciousness and control of the vehicle. This puts the driver as well as society in danger (Cerna, 1997).

Driving is considered to be a complex task, requiring the integration of several skills. Individuals are evaluated for vision, perception, and cognition. A comprehensive visual screening is a vital part of the evaluation because vision is considered to be the primary sense used while driving. Visual acuity, peripheral vision, oculomotor pursuits, field vision, night vision, glare vision, color blindness, visual scanning, visual memory, visuospatial perception, visuopraxis, near and far acuity, and saccades are often examined. The majority of states require that visual acuity be at least $20 / 50$ and corrective lenses or glasses may be needed if vision is not at this level. Perceptual skills that are often evaluated include figure ground, spatial relations, and depth perception. Visual-perceptual evaluations should include visual organization, visual search, and processing speed (Latson, 1987).

Individuals with cognitive impairments may display a lack of judgement, 
impulsiveness, and poor attention span, among other factors that may hinder their ability to drive safely. A cognitive assessment may include safety judgment, attention span, analytical processing, planning and decision making, selected and divided attention, and a general awareness of how the disability has impacted their ability to drive (Handler \& Patterson, 1995).

Motor functioning should also be evaluated to determine the range of motion that is available to an individual. This is needed in entering and exiting the vehicle and in operating different controls properly. Strength, reaction time, grip, balance, endurance, and head and trunk control, may also be assessed. A thorough evaluation compiles an individual's overall level of functioning. Strengths and weaknesses can be identified, which will determine one's capability to drive safely (Latson, 1987).

The Cybernetic Model of Driving has been suggested as a framework for a complete driving assessment. It was designed to test driving abilities, based on the information obtained through neuropsychological and behavioral tests, simulator evaluations, and actual behind the wheel tests. The model proposes to begin with initial pre-driving evaluations that will determine if the client can further participate and progress in a driving program and delineates what skills need to be improved. The Oral Symbol Digit Test, Driver Performance Test, and the Small Scale Vehicle, are psychometric tests, that are considered to be valid in predicting driving abilities. These tests will help screen those that pose a danger on the road and identify the deficits that can become a focus during treatment. The Cognitive Behavioral Driver's Inventory is the most widely used test among driving evaluators whose clients have cognitive impairments. It was developed in 1988 by Engum, Pendergrass, Cron, and Lambert, in their search for a comprehensive 
driving test. It contains neuropsychological batteries, screening of reaction time, and visual abilities. A driving performance assessment is also conducted, which includes the ability to start and stop, steer, lane use, speed and traffic control, braking, acceleration and deceleration, left and right turn, forward and backward movements, and turning of a vehicle (Sprigle, et al. 1995).

Predriving skills are evaluated, such as vehicular mobility which includes entering and exiting the vehicle, and opening and closing doors. The ability to use any needed adaptive devices is also examined. The individual must show an understanding of how to use primary and secondary controls, which are essential to driving. Primary controls include the steering wheel, brakes, and accelerator. Secondary controls include the horn, turn signal, and windshield wipers. Once the predriving skills are determined to be sufficient, the behind the wheel assessment begins. The individual begins to drive within the parking lot of the rehabilitation facility. As the individual demonstrates an ability to safely operate the vehicle, they are slowly taken into traffic, which includes a variety of situations (Koppa, 1990).

When the evaluation is complete, the driving rehabilitation team goes over the results and discuss them with the individual. A thorough driving evaluation includes the findings from the clinical, stationary, and driving assessments. Any modifications, adaptive devices, and recommendations for further training are included. When an evaluation concludes with the decision of an unsafe driver, the evaluator needs to be sensitive to the individual's needs and feelings. Alternative transportation methods can be discussed with the individual. They can be referred to the Department of Motor Vehicles to get further information on what is available within their region. Referrals to other 
sources, such as social workers and finding other solutions may ease the transition from driving oneself around to relying on other means of transportation. They may also request another evaluation depending on the state, if they were not functioning to their optimal performance due to several factors. It has been found that individuals feel more hopeful when they are told that they may take the driving evaluation at a later time (Gillins, 1990). Ethical Issues Facing Driving Evaluators

All rehabilitation driving programs need to focus on the safety of the driver, protecting them and the rights of all citizens to be free of danger and harm. An evaluator has a responsibility they must uphold to and need to be careful in their judgements. A balance needs to be achieved to ensure their client's autonomy, while protecting the general public. The possibility of being held liable for accidents, is a reality for all driving rehabilitation facilities and professionals. There have been cases when entire driving rehabilitation personnel have been held liable, due to a vehicular accident involving a client with a disability who was recommended to drive. The literature shows the need for more specific guidelines for evaluating and reevaluating disabled drivers (Galski, Bruno \& Ehle, 1992)

\section{Problems Found in Driving Evaluations}

Research shows that there is no uniform way to test disabled drivers, and that evaluators are using different forms of assessments. Deaton found that between $90-100 \%$ of evaluators tested their clients for vision and hearing, range of motion, strength, coordination, sensation, reaction time, transfers, and mobility. Evaluators reported that $90 \%$ used residential and highway training, $32 \%$ used driving simulators, $56 \%$ used verbal instructions, 56\% used visual-perceptual exercises, and 59\% used cognitive and perceptual 
training. A study was conducted on 403 evaluators working with drivers with disabilities, taken from 44 states. It was found that $62 \%$ were occupational therapists, $12 \%$ were other therapists, and $18 \%$ had an education degree. The respondents reported that $80 \%$ of the evaluations took place in medical facilities, $5 \%$ in educational facilities, and $6 \%$ took place in a driving program (Sprigle, et al. 1995).

Driving characteristics, such as brake reaction time were more important determinants of driving abilities than physical characteristics, such as grip strength. This is due to the fact that research has shown poor correlations between physical abilities and driving skills. Each individual is unique and even patients with similar diagnosis will differ in their capabilities, due to their skills prior to their accident and the degree of residual effects. It is difficult to measure one's ability to drive based solely on their physical capacities and researchers express the need for a more thorough assessment (Sprigle, et al. 1995).

\section{Driving Simulators}

Due to liability issues that practitioners face, new methods were developed that would reduce the need of road exams, placing the evaluator and client under unnecessary risks. Driving simulators imitate environments that drivers may encounter and have been proven to be cost-effective when compared to behind the wheel training (Sprigle, et al. 1995). Driving simulators have been found to have similar handling characteristics as actual behind the wheel driving (Galski, et al. 1997). The Amigo Electrical Vehicle is an example of a simulator that has been used with brain injured patients. It was found that those who had simulator training obtained higher scores than those who were trained in other methods that did not use a simulator. The results taken from the simulator training 
generalized to on the road tests, proving to be a valuable tool for practitioners. However, researchers warn examiners about the dangers of solely using a simulator because more studies need to be conducted in this area (Handler \& Patterson, 1995).

The Doran L225 Driving System/Analyzer, is a simulator that has been widely used in evaluating driving behaviors. It contains a driving seat in front of a 12 foot screen, in which two films are shown depicting driving scenarios. Attention span and the ability to follow directions, among other factors are assessed. Each subject's scores are automatically calculated by a computer, according to the number of correct and incorrect answers. Simulators such as the Doran model allow examiners to get a general idea of what their clients are capable of. However, researchers claim that they do not depict all driving situations and do not have the exact feel of driving a real car. In response to this request, a few companies began to investigate and design more realistic simulators (Galski, et al. 1997).

Systems Technology, Inc. (STI) created the STISIM, a low cost interactive driving simulator. STI has been using simulators for over 35 years for aerospace training, transportation safety, and driver behavior among those with and without impairments. The STISIM is a computer that examines a variety of skills used during driving. A steering wheel, turn signals, horn, and foot pedals are provided. It contains auditory and visual cues. The scenarios depict the driver in everyday circumstances that they may encounter. A final assessment is taken which measures various driving behaviors, such as the speed limit that was followed. The number of correct and incorrect responses are tabulated. The STISM is currently being further researched. Systems technology is providing its services to the U.S. Department of Defense, Department of Transportation, 
National Air and Space Administration, and several automotive companies, all in search for safer modes of transportation (Systems Technology, Inc., 1997).

History of Automotive Adaptive Equipment for Drivers with Disabilities

Following World War I, disabled veterans returned to America with varying forms of disabilities, including chronic head injuries and upper and lower extremity amputations. To better suit the needs of these veterans, the model T-Ford was one of the first automobiles to be adapted with hand controls and a one pedal shift. In 1935 president Franklin D. Roosevelt owned the Ford Phaeton, which was adapted with hand controls. Adapted automobiles became available to disabled veterans through the Veterans Administration. In the 1950's a two-door sedan was the typical car purchased and adapted for individuals with disabilities. However, those with more limiting disabilities could not find automobiles that could fit their needs (Koppa, 1990).

With the civil rights movement in the 1970 's, disabled individual's rights were finally heard, such as better work opportunities and access to public buildings. However, the disabled could not physically get themselves to a work site, because they lacked vehicular transportation or access to public transportation. Several automobile companies created a large van that would allow for easy access when entering and exiting, to facilitate driving for individuals with disabilities. Several organizations, such as the Veterans Administration Prosthetics Center, the U.S. Department of Health and Human Services, and the National Institute for Disabled Research, provided funding geared towards researching the needs of all drivers with disabilities to help improve the quality of their lives (Koppa, 1990).

A review of the literature shows the lack of information available on adaptive 
driving and how concern for disabled drivers is a relatively recent phenomenon (Heil, 1993). Although there is a wide variety of adaptive devices available to disabled drivers, there is a lack of consumer research done on their quality. One of the few studies conducted on adaptive devices, found that the brake reaction time among individuals with disabilities was .39 seconds faster than able-bodied drivers. This was due to the fact that their brake was located on their hand control and provided easier access (Sprigle, et al. 1995).

\section{Car Manufacturers and Disabled Drivers}

The first articles focusing on disabled drivers appeared in the late 1960's and car manufacturers began programs for physically disabled drivers in the late 1980 's. Due to the realization of the large number of disabled individuals, companies began to view this population as valuable consumers. With increasing environmental concerns, cars are being made to produce less hydrocarbons, carbon monoxides, and oxides of nitrogen. In order for this to be done vehicle designers are downsizing automobiles, making them lightweight with smaller engines, and at a more expensive price (Heil,1993).

However, this raises several issues for the disabled, since they need larger sized vehicles (Heil, 1993). For this reason, many disabled drivers choose to purchase vans. It is estimated that an adapted van for an individual with low-level quadriplegia may cost $\$ 28,500$ and a van for an individual with a high-level quadriplegia may cost up to $\$ 60,000$. However, not all individuals can afford such expensive vehicles. A vehicle can be purchased through a car dealership, which will recommend a specialist for the installation of adaptive equipment. Chrysler, Ford, and General Motors offer reimbursements for the cost of installing adaptive equipment for drivers and passengers (Boettcher, 1994). 


\section{Self-Report}

Self-report is the most commonly used form of data collection within the social sciences. Respondents are directly asked for information, through the use of questionnaires that may be mailed or collected in person and by an interview format (Barker, Pistrang \& Elliott, 1994). The use of self-reports that will be mailed has several advantages. A sufficient representation of the population can be reached and the researcher can collect data by themselves, without having to hire any staff. Information from the respondent's personal views can be collected, without interviewer bias, referred to as phenomenological data. A written questionnaire is considered to be standardized, by having each question with the same format and wording. Respondents can answer questions in the privacy of their homes and at their own pace. Individuals are considered to answer questions related to sensitive subjects more readily through questionnaires, in comparison to other forms of data collection. This is due to the fact that respondent's are usually informed when a questionnaire is mailed to them, that their answers will remain anonymous and there is no direct contact. Generally, the use of questionnaires is considered to be less expensive than other forms of data collection (Stein \& Cutler, 1996).

The use of self-reports also has several disadvantages. This includes difficulty with validity, since the information collected is subjective. Respondents may not answer questions honestly and their perceptions of reality may be somewhat distorted from the truth. The researcher is not present to clarify any questions the respondent may have (Fowler, 1993). The use of open-ended questions can be difficult for respondents to answer and for the researcher to interpret, due to a wide variability in answers (Barker, et al. 1994). Closed-ended questions are considered to be easier for the respondent to 
answer and for the researcher to interpret. However, closed-ended questions may limit a respondent's choices to the ones listed and there may not be a correct choice for them to select from. Mailing questionnaires may be time consuming for the researcher, as they wait for the respondents to mail them back. The entire data collection process is estimated to take at least 2 months. A segment of the population may not return the questionnaires, if they have poor reading and writing skills, inadequate vision, or do not understand the English language well. It is difficult for the researcher to determine which individuals will return the questionnaire. Individuals who are interested in the questionnaire topic are more likely to mail it back to the researcher. It is estimated that less than $50 \%$ of individuals will mail their questionnaires back to the researcher, if respondent's are not reminded to return them (Fowler).

\section{The Model of Human Occupation}

The model of human occupation (MOHO) is a general systems theory which incorporates the environment, psychology, sociology, and biology into its basic concepts. The MOHO is considered to be a holistic model that can guide occupational therapists throughout the treatment of their clients, such as in a driving rehabilitation program. The MOHO reflects on the well-being of individuals, as well as the impact of a disability. When a person's life becomes affected by an illness or trauma, dysfunction occurs. Individuals may start to feel helpless and experience a sense of loss due to their disability. They may not be able to continue in their previous roles that they were once successful at. An imbalance occurs and maladaptive responses may be made in an effort to maintain a sense of harmony. Occupational therapy seeks to restore, maintain, or enhance one's health by promoting the use of functional activities to fulfill their occupational roles 
successfully (Kielhofner, 1985).

The MOHO and occupational therapy both identify humans as being occupational in nature and consider a variety of activities in which they take part. They both view individuals as being able to achieve their goals through active participation. Within occupational therapy, occupation is described in terms of work, play, and daily living activities, which are all interconnected. When a person experiences a disability, such as a spinal cord injury, this causes a disruption in their life. Many of their former activities may be affected, such as driving (The American Occupational Therapy Association, 1993).

Functional activities are used in therapy to achieve an end goal for the patient. The MOHO literature shows that the use of activity provides feedback to the client about their performance. Feelings of incompetence can be explored during treatment sessions, as clients begin to work on achieving their goals. Driving is the activity and occupation that is continuously evaluated in a driving rehabilitation program. The client is given information about their performance, in which recommendations specific to the individual's needs are given (Sprigle, et al. 1995).

The MOHO describes a hierarchy of subsystems that determine how one functions within the environment, and includes the volition, the habituation, and the performance subsystems. These subsystems can guide those working with drivers who have disabilities. The volition subsystem is considered to be the highest level and is responsible for motivating individuals to work towards their goals. Individuals going through a driving rehabilitation program need to accept their disability in order to keep them motivated to drive again or for the first time. The motivating factor for human behavior comes from an innate need to master one's environment. During this stage, an individual determines what 
action needs to be taken by examining their situation. Occupational therapists in a driving rehabilitation program begin treatment by examining their patient's values and interests. Values determine what is important to an individual. Interests help prioritize what occupations an individual will participate in. By working together with the patient, appropriate goals can be reached that will allow the individual to overcome the obstacles imposed by their disability (Bruce \& Borg, 1993).

The habituation subsystem is in the center of the hierarchy, which includes habits and roles. Habits serve to organize one's behavior and roles determine one's self-identify and appropriate behavior within their environment. The MOHO describes a need to have a balance in the roles one performs. With a disability, the loss of roles may occur, such as not being able to drive oneself to needed or desired places. In order to plan treatment appropriately, driving evaluators need to consider the client's roles prior to their disability and what roles they plan to continue to fulfill. Short-term and long-term goals can be established to determine a level of regression or progress towards one's goals. It is important for the patient to select those roles that are important to them in order for them to be motivated enough to fulfill them (Kielhofner, 1985).

The performance subsystem is the lowest system and includes the skills needed to participate in occupations, such as perceptual-motor skills. Driving is an activity that requires the integration of several skills simultaneously. Drivers with disabilities may have a few or several skills that they need to work on in order to fulfill their roles within society (Bruce \& Borg, 1993).

After establishing appropriate values, interests, habits, roles, and skills for their patients, occupational therapists in a driving rehabilitation program can begin to implement 
individualized treatment. This will vary among individuals and throughout treatment, goals need to be reevaluated and modified. The MOHO can be extremely useful for therapists in determining the best form of treatment. The principles of the MOHO facilitate occupational therapy treatment. Individuals can experience feelings of competency by working on their skills and deficits used in driving. This may lead to a better match with the environment (Sprigle, et al. 1995). 


\section{Chapter III}

\section{Methodology}

\section{Objective and Research Questions}

The objective of this study was to examine how autonomy is affected among individuals with spinal cord injuries by being able to drive again or for the first time, through participating in a driving rehabilitation program.

Five research questions were addressed in this study:

1. What level of autonomy do individuals with spinal cord injuries who have gone through a driving rehabilitation program experience?

2. Do individuals with spinal cord injuries who have gone through a driving rehabilitation program experience a sense of improved autonomy in their life?

3. Is there a difference in the amount of time individuals spent driving before their injury, disability, or condition to after their injury, disability, or condition and going through a driving rehabilitation program?

4. Is there a difference in driving-related autonomy of individuals by level of spinal cord lesion after going through a driving rehabilitation program?

5. Are there differences in driving-related autonomy of individuals with spinal cord injuries by age, marital status, gender, education, ethnicity, and employment status after going through a driving rehabilitation program?

Subjects

A questionnaire (Appendix B) was mailed to 65 individuals with spinal cord injuries of all levels who had completed a driving rehabilitation program at Advanced Driving. The subjects that were selected had completed a driving rehabilitation program 
within the last three years (1996 to 1999). Thirty three of the questionnaires that were mailed were returned. In order to maximize the sample, subjects were also recruited from the Miami Project to Cure Paralysis. These individuals had spinal cord injuries of all levels and had also completed a driving rehabilitation program within the last three years. The surveys were hand delivered and collected from a therapist at the Miami Project to Cure Paralysis, who was responsible for implementing the surveys to the subjects. A total of twenty surveys were collected. The subjects who met the following criteria were included in the study: (1) the subject sustained a spinal cord injury, (2) was over the age of 18 , and (3) had completed a driving rehabilitation program. All subjects were required to read and write in the English language, or have assistance from someone to correctly complete the survey. Of the 53 surveys collected, 52 met the above criteria and were included in the study. The subjects' confidentiality was upheld by coding each questionnaire with an identification number, since some individuals wrote their names on the survey. Human subjects' approval was obtained through Florida International University. Permission to conduct the study was given by Advanced Driving and the Miami Project to Cure Paralysis.

\section{Data Collection}

The survey instrument was created by the researcher who is a candidate for a Master of Science degree in Occupational Therapy at Florida International University. The first part of the questionnaire contained 14 questions related to demographic information. The second part of the questionnaire contained 10 questions related to autonomy, in which a Likert-scale was used to rate responses. The scale contained five choices in a five point scale: 1 = strongly agree, 2 =agree, $3=$ undecided, $4=$ disagree, 
and 5 = strongly disagree. On question \#24 respondents were asked to select a percentage related to autonomy as follows: $1=$ strongly agree $(100 \%), 2=$ agree $(75 \%), 3=$ undecided $(50 \%), 4=$ disagree $(25 \%)$, and $5=$ strongly disagree (less than $25 \%$ ).

A pilot study was conducted to determine the clarity of the instructions, questions, and overall format of the questionnaire. The pilot questionnaire was given to 7 individuals with disabilities who were driving. Their suggestions were taken into consideration in refining the final copy of the questionnaire.

A cover letter (Appendix A) describing the purpose of the study and the questionnaire, were provided to all participants in the study. The cover letter explained that all responses to the questionnaire would remain anonymous. A self-addressed stamped envelope was included for the 65 surveys that were mailed.

\section{Statistical Analyses}

Descriptive statistics such as frequencies, percentages, means, standard deviations, and cross tabulations were calculated for demographic and research variables. Pearson's correlation was used to identify the extent of the relationship between the autonomy scale and question \#24. Two cross tabulations were performed to determine differences between the amount of time individuals spent driving before and after their injury, disability, or condition and going through a driving rehabilitation program. A one-way ANOVA was used to identify significant differences between subjects by level of spinal cord lesions and level of autonomy. All data analysis was carried out using the statistical package for the social sciences (SPSS). Results were considered statistically significant at the $\mathrm{p} \leq .05$ level. 


\section{Limitations of the Study}

Generalizations from the results of this study to the population of individuals with spinal cord injuries who have gone through a driving rehabilitation program is limited due to the following reasons:

1. The participants used in the study were limited to those from Advanced Driving and the Miami Project to Cure Paralysis. Results may not be representative of all individuals with spinal cord injuries who have gone through a driving rehabilitation program, making generalizations difficult.

2. Limitations in statistical significance may have occurred, since a small sample size of 52 individuals was used.

3. Only individuals with spinal cord injuries were examined, eliminating other disability categories from the study.

4. Self-selection bias may have occurred since the questionnaires were returned on a voluntary basis.

5. An original questionnaire was used in the study, in which only face validity was established. 


\section{Chapter IV}

\section{$\underline{\text { Results }}$}

\section{Demographics}

Thirty three of the 65 questionnaires that were mailed to individuals with spinal cord injuries from Advanced Driving were returned. This represents a $51 \%$ return rate for the questionnaires that were mailed. Of the questionnaires returned, 33 met all inclusive criteria which included the following: (1) the subject sustained a spinal cord injury, (2) were over the age of 18 , and (3) completed a driving rehabilitation program. Twenty questionnaires were hand delivered and collected from a therapist at the Miami Project to Cure Paralysis. Nineteen of the questionnaires met the inclusive criteria and were included in the study. One survey was not included in the study because it was incorrectly filled out. Only the data from the 52 questionnaires was included in the data analysis for this study. All subjects completed every question on the survey.

All demographic data is summarized in Table 1 . Of the fifty two subjects, 46 $(88.5 \%)$ were male and $6(11.52 \%)$ were female. The subjects ranged in age from 20 to 74 years, with a mean age of 36 . There was $6(11.5 \%)$ Black/African American subjects, $31(59.6 \%)$ White/Caucasian subjects, and 15 (28.8\%) Hispanic subjects. Twenty $(38.5 \%)$ of the respondents had a $\mathrm{C} 6$ to $\mathrm{C} 8$ spinal cord lesion, $10(19.2 \%)$ had a T1 to T5 spinal cord lesion, $7(13.5 \%)$ had a T6 to T8 spinal cord lesion, $9(17.3 \%)$ had a T9 to T12 spinal cord lesion, and 6(11.5\%) had an L1 to L5 spinal cord lesion.

The original marital status question contained in the survey was collapsed, for the purpose of running the statistical test. The new categories included never married, 
Table 1

Frequencies and Percentages of Demographic Data of Subjects $(\underline{N}=\mathbf{5 2})$

$\begin{array}{lll}\text { Variables } & \text { f } & \%\end{array}$

Gender

Male

46

$88.5 \%$

Female

6

$11.5 \%$

Ethnicity

Black/African American

6

$11.5 \%$

White/Caucasian

31

$59.6 \%$

Hispanic

15

$28.8 \%$

Level of Spinal Cord Lesion

$\mathrm{C} 6$ to $\mathrm{C} 8$

20

$38.5 \%$

$\mathrm{T} 1$ to $\mathrm{T} 5$

10

$19.2 \%$

T6 to T8

7

$13.5 \%$

T9 to T12

9

$17.3 \%$

$\mathrm{L} 1$ to $\mathrm{L} 5$

6

$11.5 \%$

\section{Marital Status}

Never Married

26

$50.0 \%$

Divorced/Widowed/Separated

8

$15.4 \%$

Married

18

$34.6 \%$ 
Table 1 (continued)

Frequencies and Percentages of Demographic Data of Subjects $(\underline{N}=52)$

Variables

f

$\%$

Educational Level

Some or Completed High School

$22.9 \%$

Some College

24

$50.0 \%$

College Graduate

13

$27.1 \%$

\section{Work Status}

Employed

$43.1 \%$

Unemployed

$43.1 \%$

Student

Have access or ownership to a vehicle

Have adaptations to vehicle

Vehicle Type

2 door sedan

4 door sedan

9

$17.3 \%$

Van

$51.9 \%$

Sports Utility Vehicle

3

$5.8 \%$

Jeep

2

$3.8 \%$

Note: $\mathbf{n}=$ number of subjects.

$\%=$ valid percentage. 
divorced/widowed/separated, and married. Twenty six (50.0\%) of the respondents were never married, $8(15.4 \%)$ were divorced/widowed, or separated, and $18(34.6 \%)$ were married. The question on education was collapsed to include some high school or high school graduate, some college, and college graduate. Eleven $(22.9 \%)$ of the respondents completed some or graduated from high school, 24 (50.0\%) completed some college, and $13(27.1 \%)$ graduated from college. The question on work status was collapsed to include employed, unemployed, and student. Twenty two (43.1\%) of the respondents were employed, $22(43.1 \%)$ were unemployed, and $7(13.7 \%)$ were students.

All 52 subjects $(100 \%)$ reported to own or have access to a vehicle. Fifty one (98.1\%) of the respondents had adaptations to their vehicles which allowed them to drive, and $1(1.9 \%)$ did not have any adaptations. Eleven $(21.2 \%)$ of the subjects owned or had access to a 2 door sedan, $9(17.3 \%)$ owned or had access to a 4 door sedan, $27(51.9 \%)$ owned or had access to a van, $3(5,8 \%)$ owned or had access to a sports utility vehicle, and $2(3.8 \%)$ owned or had access to a jeep (See Table 1).

In response to the question, "Before your injury, disability, or other condition that caused your inability to drive, how did you usually get around?", 34 (65.4\%) drove a vehicle, and $18(34.6 \%)$ used public transportation/friends or family would drive. In response to the question, "How do you currently get around?", 51 (98.1\%) drove a vehicle and $1(1.9 \%)$ used public transportation/friends or family would drive.

In response to the question, "How often did you drive before your injury, disability, or other condition?", $34(65.4 \%)$ drove once or more daily, $8(15.4 \%)$ drove once or more a week, and $10(19.2 \%)$ drove less than weekly. In response to the question, "How often are you currently driving?", 44 (84.6\%) drove once or more daily, 
and $8(15.4 \%)$ drove once or more a week. None of the respondents $(0 \%)$ drove less than weekly (See Table 2).

\section{Descriptive Statistics}

An autonomy scale was created for questions \#15 through \#23. Higher scores were associated with higher levels of autonomy. Subjects were asked to respond to a five point Likert scale, in which strongly agree was given a score of 5 , agree was given a score of 4 , undecided was given a score of 3 , disagree was given a score of 2 , and strongly disagree was given a score of 1 . The mean for the autonomy score among the 52 participants on a five point scale was $(\underline{M}=4.73)$ and the standard deviation was $(\underline{S D}=$ 326). Question \#24 was considered to be a global question on autonomy and was not included in the scale, but analyzed separately. The mean for question $\# 24$ on a five point scale was $(\underline{M}=4.65)$ and the standard deviation was $(\underline{\underline{S D}}=.683)$. Pearson's correlation was used to analyze the data in order to identify correlations between the autonomy scale (questions \#15 through \#23) and question $\# 24$, because they were analyzed separately. There was a significant positive correlation between the autonomy scale scores and question \#24 ( $r=0.45, p \leq 0.001)$. These findings show that the autonomy scale (questions \#15 through \#23) and question \#24 were both measuring the variable of autonomy.

Frequencies and Percentages of Survey Responses

Frequencies and valid percentages were analyzed for each of the responses to the statements on the questionnaire (See Table 3 and Table 4). Each statement was specific to autonomy and driving. 
Table 2

Frequencies and Percentages of Demographic Data of Subjects $(N=52)$

Survey question $\quad$ f $~ \%$

11. Before your injury, disability or other

condition that caused your inability to drive,

how did you usually get around?

Drove vehicle

Public transportation/friends or family

would drive
34

$65.4 \%$

18

$34.6 \%$

12. How do you currently get around?

Drive vehicle

Friends or family will drive
51

1
$98.1 \%$

$1.9 \%$

13. How often did you drive before your injury, disability or other condition?

Once or more daily

Once or more a week

Less than weekly

14. How often are you currently driving?

Once or more daily

Note: $\mathbf{m}=$ number of subjects.

$\%=$ valid percentage 
Table 3

Frequencies and Percentages of Responses to Survey Questions $(\mathbf{N}=\mathbf{5 2})$

Survey questions Strongly Agree Agree Undecided Disagree Strongly Disagree

15. Being able to drive a $\quad 50(96.2 \%) \quad 2(3.8 \%) \quad 0(0 \%) \quad 0(0 \%) \quad 0(0 \%)$

vehicle is very important

tome.

16. I feel comfortable and $47(90.4 \%) \quad 5(9.6 \%) \quad 0(0 \%) \quad 0(0 \%) \quad 0(0 \%)$ confident driving.

17. I am independent in $\quad 34(65.4 \%) \quad 10(19.2 \%) \quad 0(0 \%) \quad 7(13.5 \%) \quad 1(1.9 \%)$ most or all of my

daily activities.

18. I feel more in control $45(86.5 \%) \quad 7(13.5 \%) \quad 0(0 \%) \quad 0(0 \%) \quad 0(0 \%)$

of my life when I can drive

myself to complete work

tasks.

19. I feel more in control $\quad 42(80.8 \%) \quad 8(15.4 \%) \quad 2(3.8 \%) \quad 0(0 \%) \quad 0(0 \%)$ of my life when I can drive

myself to obtain medical and self-care needs. 
Table 3 (continued)

Frequencies and Percentages of Responses to Survey Questions $(\underline{\mathbf{N}}=\mathbf{5 2})$

\begin{tabular}{llllll}
\hline \hline Survey questions & Strongly Agree & Agree & Undecided Disagree Strongly Disagree \\
\end{tabular}

20. I feel more in control $44(84.6 \%) \quad 6(11.5 \%) \quad 2(3.8 \%) \quad 0(0 \%) \quad 0(0 \%)$

my life when I can drive

myself to sports, musical

events, and other recreational

activities.

21. I feel more in control $42(80.8 \%) \quad 9(17.3 \%) \quad 1(1.9 \%) \quad 0(0 \%) \quad 0(0 \%)$

my life when I can drive

myself to do food, clothes,

and other shopping.

22. Overall, I feel confident $39(75.0 \%) \quad 10(19.2 \%) \quad 2(3.8 \%) \quad 1(1.9 \%) \quad 0(0 \%)$

and in control of my life.

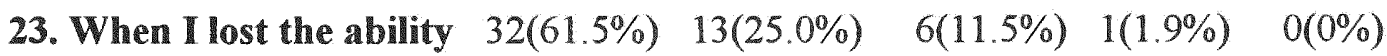

drive, I felt like many of

my freedoms had been

taken away from me.

Note: $\mathbf{n}=$ number of subjects.

$\%=$ valid percentage. 
Table 4

Frequencies and Percentages of Responses to Survey Question $\# 24(\underline{N}=52)$

\begin{tabular}{llllll}
\hline \hline Survey question & $100 \%$ & $75 \%$ & $50 \%$ & $25 \%$ & $\leq 25 \%$ \\
\hline
\end{tabular}

24. Being able to drive $\quad 40(76.9 \%) \quad 6(11.5 \%) \quad 6(11.5 \%) \quad 0(0 \%) \quad 0(0 \%)$ again or for the first time has improved my life by....

Note: $\mathbf{n}=$ number of subjects.

$\%=$ valid percentage. 


\section{Relevance of Driving}

Questions \#15 and \#16 were specific to respondents' perceptions about the relevance and level of confidence in driving. Question \#15 was, "Being able to drive a vehicle is very important to me." Fifty $(96.2 \%)$ strongly agreed and $2(3.8 \%)$ agreed with this statement. Question \#16 was, "I feel comfortable and confident driving." Forty seven $(90.4 \%)$ strongly agreed and $5(9.6 \%)$ agreed with this statement (See Table 3 ). Autonomy, Driving and Daily Activities

Questions \#17 through $\# 21$ were specific to respondents' perceptions about autonomy and driving to complete daily activities. Question \#17 was "I am independent in most or all of my daily activities." Thirty four $(65.4 \%)$ strongly agreed, $10(19.2 \%)$ agreed, $7(13.5 \%)$ disagreed, and $1(1.9 \%)$ strongly disagreed with this statement. Question \#18 was "I feel more in control of my life when I can drive myself to complete work tasks." It was found that $45(86.5 \%)$ strongly agreed and $7(13.5 \%)$ agreed with this statement. Question \#19 was "I feel more in control of my life when I can drive myself to obtain medical and self-care needs." Forty two (80.8\%) strongly agreed, 8 (15.4\%) agreed, and $2(3.8 \%)$ were undecided about this statement. Question \#20 was "I feel more in control of my life when I can drive myself to sports, musical events, and other recreational activities." Forty four (84.6\%) strongly agreed, $6(11.5 \%)$ agreed, and 2 (3.8\%) were undecided about this statement. Question \#21 was "I feel more in control of my life when I can drive myself to do food, clothes and other shopping. Forty two $(80.8 \%)$ strongly agreed, $9(17.3 \%)$ agreed, and $1(1.9 \%)$ were undecided about this statement (See Table 3). 


\section{Autonomy and Driving}

Questions \#22 through \#24 were specific to respondents' perceptions about the influence driving has on one's feelings of autonomy and life satisfaction. Question $\# 22$ was, "Overall, I feel confident and in control of my life." Thirty nine (75.0\%) strongly agreed, $10(19.2 \%)$ agreed, $2(3.8 \%)$ were undecided, and $1(1.9 \%)$ disagreed with this statement. Question \#23 was "When I lost the ability to drive, I felt like many of my freedoms had been taken away from me." Thirty two (61.5\%) strongly agreed, 13 $(25.0 \%)$ agreed, $6(11.5 \%)$ were undecided, and $1(1.9 \%)$ strongly disagreed with this statement (See Table 3).

Question \#24 was considered to be a more general statement and respondents were asked to select a percentage. It stated 'Being able to drive again or for the first time has improved my life by $\ldots 100 \% .75 \%, 50 \%, 25 \%$, or less than $25 \%$." Subjects were asked to select as follows: 100\% (It improves my life on a daily basis), $75 \%$ (It improves my life 5-6 days a week), 50\% (It improves my life 3-4 days a week), 25\% (It improves my life 1-2 days a week), less than 25\% (It improves my life occasionally but not on a consistent basis). The results showed that $40(76.9 \%)$ of the respondents believed that driving had improved their life by $100 \%, 6(11.5 \%)$ believed that driving had improved their life by $75 \%$, and $6(11.5 \%)$ believed that driving had improved their life by $50 \%$ (See Table 4).

\section{Cross Tabulations}

Cross tabulations were performed to determine differences between the driving behaviors among subjects. Comparisons were made to how often individuals drove before their injury, disability or condition to how often individuals drove after going through a 
driving rehabilitation program. It was found that $33(97.1 \%)$ of the subjects who drove before their injury, disability or condition also drove after, 18 (35.3\%) of the subjects who did not drive before their injury, disability or condition drove after, and $1(2.9 \%)$ of the subjects who drove before their injury, disability or condition used public transportation, or had friends and family drive (See Table 5). It was also found that $32(61.5 \%)$ of the subjects drove the same amount of time, $16(30.7 \%)$ drove more, and $4(7.7 \%)$ drove less than they use to before their injury, disability, or condition (See Table 6).

\section{$\underline{\text { Statistical Analysis }}$}

\section{Differences between subjects by level of spinal cord lesions and level of autonomy}

Comparisons among subjects by level of spinal cord lesion and level of autonomy were computed by a one-way ANOVA test. On question \#4 subjects selected their spinal cord lesion level, among seven different categories (See Table 1). A statistically significant difference was found in the autonomy score for question $\# 24$, by the level of spinal lesion $\underline{F}(4,47)=2.60, \underline{p} \leq .05$. Therefore, Fisher's LSD post-hoc test was performed at the $5 \%$ level to determine which groups differed. The T6 to T8 group differed significantly from the $\mathrm{T} 1$ to $\mathrm{T} 5$ group, the T9 to T12 group, and the L1 to L5 group. The T6 to T8 group was found to have lower levels of autonomy in comparison to the T1 to T5 group, the T9 to T12 group, and the L1 to L5 group (See Table 7). 
Table 5

Differences Among Subjects in Driving Behaviors $(\underline{N}=\mathbf{5 2})$

Variables

I

$\%$

Subjects who drove before their

$97.1 \%$

injury, disability, or other condition

and drove after going through a

driving rehabilitation program.

Subjects who did not drive before

their injury, disability or condition

and drove after.

Subjects who drove before their injury,

disability or condition, but used public

transportation or had friends and family

drive after.

Note: $\mathrm{n}=$ number of subjects.

$\%=$ valid percentage. 
Table 6

Driving Differences After Participating in a Driving Rehabilitation Program $(\underline{N}=52)$

Variables

f

$\%$

Subjects who drove the

32

$61.5 \%$

same amount of time

Subjects who drove more

16

$30.7 \%$

Subjects who drove less

4

$7.7 \%$

Note: $\mathbf{n}=$ number of subjects

$\%=$ valid percentage. 
Table 7

Significant Differences Between Subjects by Level of Spinal Cord Lesion

and Autonomy

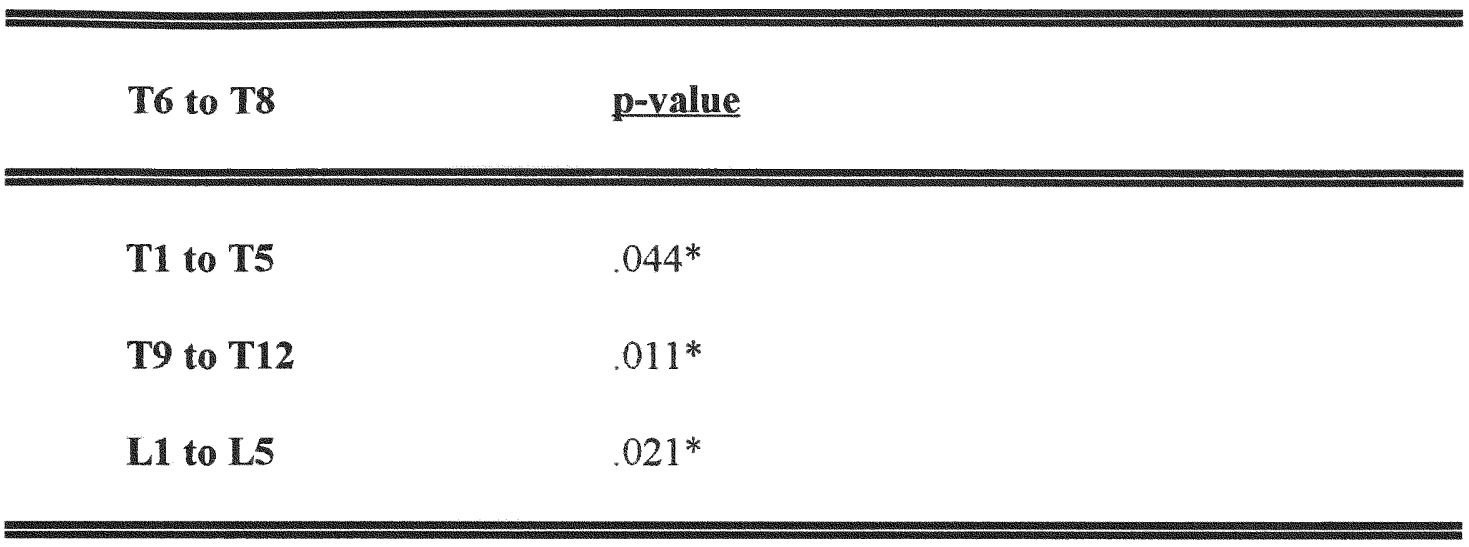

Note: *indicates a significant difference at $\mathrm{p} \leq .05$. 
Table 8

Means and Standard Deviations of Spinal Cord Lesion Levels and Autonomy

\begin{tabular}{lll} 
Variables & $\underline{\mathbf{M}}$ & $\underline{\mathrm{SD}}$ \\
\hline \hline T6 to T8 & 4.14 & 1.07 \\
T1 to T5 & 4.80 & .423 \\
T9 to T12 & 5.00 & .000 \\
$\mathbf{L 1}$ to $\mathbf{L 5}$ & 5.00 & .000 \\
\hline \hline
\end{tabular}

Note: $\underline{M}=$ mean.

$\underline{\mathbf{S D}}=$ standard deviation. 
Comparisons between the groups were made by examining the means and standard deviations. The mean and the standard deviation for the T6 to T8 group was $(\underline{M}=4.14)$ $(\underline{S D}=1.07)$, the mean and the standard deviation for the T1 to T5 group was $(\underline{M}=4.80)$ $(\mathrm{SD}=.427)$, the mean and the standard deviation for the $\mathrm{T} 9$ to $\mathrm{T} 12$ group was $(\underline{M}=5.00)$ $(\mathrm{SD}=.000)$, and the mean and the standard deviation for the $\mathrm{L} 1$ to $\mathrm{L} 5$ group was $(\underline{\mathrm{M}}=$ 5.00) $(\mathrm{SD}=.000)($ See Table 8$)$

Differences between subjects by age, marital status, gender, education, ethnicity, and employment status.

Multiple comparisons among subjects by age, marital status, education, ethnicity, and employment status were computed by a one-way ANOVA test. No significant differences were found for any of these variables among the subjects $(p \leq .05)$. Forty six subjects were male and only 6 were female. Due to the small number of female subjects, a statistical T-test could not be performed to find gender differences. 


\section{Chapter V}

\section{Discussion}

The findings from this study supported the five research questions that were addressed. The characteristics of the subjects who participated in the study and possible implications are also discussed in this chapter.

\section{Characteristics of Subjects}

Several demographic characteristics of the subjects in this study were investigated. The majority of the subjects were males with a mean age of 36 . There were few female participants in the study. These findings are consistent with the findings of Frank et al. (1998), that found that the majority of spinal cord injuries occur more often among younger males in comparison to females. The majority of the participants in this study were White/Caucasian and Hispanic. However, these results are representative of the subjects used in this study who lived in the state of Florida. The findings from this study must be interpreted with caution, since the majority of individuals in Florida have been found to have automobiles (U.S. Census Bureau, 1990).

The majority of subjects had a $\mathrm{C} 6$ to $\mathrm{C} 8$ lesion (38.5\%). This is interesting to note because the literature shows that the higher the lesion in the spinal cord, the worse the prognosis. Yet, it appears that in this study this was the largest group of individuals represented. They had all successfully completed a driving rehabilitation program. Gerhart et al. (1992) found that individuals with an incomplete spinal cord lesion were expected to have a better prognosis. However, it is not known as to whether the individuals in this study had an incomplete or a complete lesion. Future research may include a question on the survey used in this study, as to whether the subjects had an 
incomplete or a complete lesion to better interpret the results.

The majority of the subjects had completed some college or had graduated from college. The majority of the subjects were also employed or were currently students. These findings are consistent with the findings of Krause (1996), who found that there was a positive correlation between individuals with spinal cord injuries with more years of education and a higher employment rate. However, it has also been found that employment rates vary considerably among those with spinal cord injuries. They usually do not reenter the work force or further their education until 2 to 5 years after their injury (Crisp, 1990). Future research can include a question on the survey used in this study, as to how long ago the subjects' spinal cord injuries occurred in order to better interpret the results.

All of the subjects owned or had access to a vehicle, and almost everyone had adaptations to their vehicle which allowed them to drive. These findings support the literature that found that individuals with a $\mathrm{C} 5$ to $\mathrm{L} 2$ spinal cord lesion may drive with adaptations (Pedretti, 1996). The majority of the subjects had an adapted van, which allowed them to drive. These findings also support the literature that indicates that a van is the most commonly used vehicle among individuals with disabilities. According to Heil (1993), larger vehicles have been found to better accommodate individuals with disabilities. The majority of individuals with disabilities can not afford an adapted vehicle, because they can be very costly. The results of this study might suggest that the subjects in this study may have been more financially stable or received more financial support, in comparison to other individuals with spinal cord injuries. 
The first research question addressed was, "What level of autonomy do individuals with spinal cord injuries who have gone through a driving rehabilitation program experience?" Responses to the statements on the survey relating to autonomy, indicated that the majority of individuals experienced a high level of autonomy after going through a driving rehabilitation program. The results showed that the majority of subjects believed that being able to drive a vehicle was very important to them. These findings support the literature which has shown that for many individuals with spinal cord injuries, independence through mobility is greatly valued (Sprigle, et al. 1995). The results from this study are also consistent with the findings of Jones et al. (1983), that for many individuals with spinal cord injuries, driving is perceived as being extremely important and related to autonomy.

The majority of subjects believed that they felt more in control of their life when they were able to drive themselves to perform daily activities. These results are consistent with the findings in the literature that found that individuals with spinal cord injuries place a great emphasis on being able to perform activities of daily living as independently as possible (Sprigle, et al. 1995). By being able to drive, individuals were able to take care of their own necessities, which allowed them to remain autonomous.

The majority of the subjects felt confident and in control of their life. They believed that when they lost the ability to drive, they felt like many of their freedoms had been taken away from them. These findings are consistent with the literature that has found that when a spinal cord injury occurs, individuals may feel as if they have been separated from their previous life (Sprigle, et al. 1995). A driver's license has been found to be greatly valued, and driving is considered by many to be an essential daily activity 
(Lillie, 1993).

The second research question addressed was, "Do individuals with spinal cord injuries who have gone through a driving rehabilitation program experience a sense of improved autonomy in their life?"' The responses to the survey suggest that going through a driving rehabilitation program may improve an individual's sense of autonomy. The majority of individuals believed that driving had improved their life by $100 \%$ on a daily basis. The results indicated that none of the individuals perceived being able to drive again or for the first time as improving their lives by less than $50 \%$. These findings are consistent with the literature that has found that driving can significantly improve an individual's life, and in particular their sense of autonomy. They are also consistent with the literature that once individuals can drive safely, they will experience an increase in their level of autonomy (Sprigle, et al. 1995).

The third research question addressed was, "Is there a difference in the amount of time individuals spent driving before their injury, disability, or condition to after their injury, disability, or condition and going through a driving rehabilitation program?" The responses to this question suggest that the individuals in this study drove more often after going through a driving rehabilitation program. The findings from this study are consistent with researchers who have found that individuals with spinal cord injuries will drive more frequently with training and recommendations, from a driving rehabilitation program (Sprigle, et al, 1995). The results from this study found that the majority of individuals who drove prior to their injury, disability, or condition, also drove after going through a driving rehabilitation program. There was also an increase in the number of subjects who did not drive before their injury, disability, or condition by $35.3 \%$. 
Only 4 individuals drove less than they did before their injury, disability, or condition. Although they drove less, they were still driving. These results indicate that participating in a driving rehabilitation program allowed the subjects to maintain or enhance their autonomy through driving. These findings are also consistent with the literature that has shown that every individual going through a driving rehabilitation program is unique. They will show differences in their abilities, due to the extent of the injury and residual effects (Sprigle, et al. 1995). It is possible that the individuals who drove less may have had a more recent and severe injury in comparison to the other subjects in the study, or they may be driving less due to other factors.

The fourth research question addressed was, "Is there a difference in driving-related autonomy of individuals by level of spinal cord lesion after going through a driving rehabilitation program?" The results from this study indicated that there was a lower level of driving-related autonomy for the subjects who had a T6 to T8 lesion, in comparison to those in the $\mathrm{T} 1$ to $\mathrm{T} 5, \mathrm{~T} 9$ to $\mathrm{T} 12$, and $\mathrm{L} 1$ to $\mathrm{L} 5$ spinal cord lesion groups. There is a lack of literature on spinal cord lesion levels and driving-related autonomy. The literature has found that a worse prognosis was associated with higher spinal cord lesions. These findings are consistent in showing higher levels of autonomy for individuals with a T9 to T12 and an L1 to L5 spinal cord lesion, in comparison to those in the T6 to T8 spinal cord lesion group. However, the results of this study also found that individuals with a T6 to T8 spinal cord lesion had lower levels of autonomy than those with higher spinal cord lesions, such as those in the T1 to T5 group. This may indicate that the individuals in the T6 to T8 category may have had lower levels of autonomy in comparison to those in the $\mathrm{T} 1$ to $\mathrm{T} 5$ group, due to several unknown factors. 
The fifth research question addressed was, "Are there differences in driving-related autonomy of individuals with spinal cord injuries by age, marital status, gender, education, and employment status after going through a driving rehabilitation program? No statistically significant differences among these variables were found in this study. This is consistent with the findings of Frank et al. (1987), which showed that it is difficult to find differences among individuals with disabilities, in reference to autonomy. Researchers conclude that individuals with disabilities come from a variety of settings and it is difficult to categorize them according to specific characteristics.

\section{Recommendations}

The findings from this study have examined driving-related autonomy among individuals with spinal cord injuries. However, it is difficult to determine from this study which variables were truly affected by participating in a driving rehabilitation program. Further studies examining driving-related autonomy are greatly recommended, due to the lack of research in this area. Reliability and validity testing on the survey instrument created for the purpose of this study is necessary to better assess its usefulness as a research tool.

The most prominent limitation of this study was the small sample size used. A larger sample size may have revealed more significant differences between the subjects. Future studies examining driving-related autonomy on a national level are needed to determine how relevant driving is perceived to be throughout the country among individuals with spinal cord injuries. Further studies examining driving-related autonomy among individuals with other forms of disabilities are also needed to examine which groups have higher levels of autonomy and why. 
Experimental studies, which include a pre and post-test would better indicate the effects of a driving rehabilitation program on individuals with spinal cord injuries. A question pertaining to whether the subjects had an incomplete or a complete lesion, and how long ago the subjects' spinal cord injury occurred, would allow for more accurate interpretations. There is also a need for more longitudinal studies on driving rehabilitation programs to examine how they affect their participants' level of autonomy over time.

\section{Summary}

This study conducted has offered valuable information on driving-related autonomy among individuals with spinal cord injuries. The literature showed how little importance was given to the psychosocial aspects of driving rehabilitation programs, such as autonomy, which this study has examined. However, the results obtained from this study can not be generalized beyond this sample, due to the small number of subjects used. The findings from this study suggest that individuals with spinal cord injuries who have completed a driving rehabilitation program show high levels of driving-related autonomy. This information is helpful to all professionals working with individuals who have spinal cord injuries, in demonstrating the importance that being able to drive again or for the first time has on this population. These findings can also be helpful to all individuals with disabilities who may benefit from a driving rehabilitation program.

This study has added knowledge to the areas of autonomy and disability, which have been greatly lacking. It is hoped that this study will encourage others to further research driving-related autonomy among individuals with all types of disabilities. This study has also validated the many benefits that a driving rehabilitation program may offer. 


\section{References}

Bachelder, J., \& Hilton, C.L. (1994). Implications of the Americans with disabilities act of 1990 for elderly persons. The American Journal of Occupational Therapy, 48,73 .

Bailey, D.M. \& Schwartzberg, S.L. (1995). Ethical and legal dilemmas in occupational therapy. (1st ed.). Pennsylvania: F.A. Davis Company.

Barker, C., Pistrang, N., \& Elliott, R. (1994) Wiley series in clinical psychology: Research methods in clinical and counseling psychology. (1st. ed.). New York, NY: John Wiley \& Sons Ltd.

Berg, J. (1998). On the road again. OT Week, 12(6), 16-17.

Boettcher, B.B. (1994). Will smaller cars limit your mobility? Accent on Living $\underline{39}(2), 48$.

Breske, S. (1994). The drive for independence. Advance Rehabilitation, 3(8), $10-19$.

Bruce, M.A., \& Borg, B. (1993). Psychosocial occupational therapy: Frames of references for intervention. (2nd ed.). New Jersey: SLACK Inc.

Burnett, S.E., \& Yerxa, E.J. (1980). Community based and college based needs assessment of physically disabled persons. The American Journal of Occupational Therapy, 34(1), 201.

Cairns, D., \& Baker, J. (1993). Adjustment to spinal cord injury: A review of coping styles contributing to the process. Journal of Rehabilitation, 59(4), 30-34.

Carr, D. B. (1993). Assessing older drivers for physical and cognitive impairment. Geriatrics, $48,46-51$. 
Cerna, R.G. Association of driver educators for the disabled: An international organization. (1997). Edgerton, WI.

Cicirelli, V.G. (1992). Family caregiving: autonomous and paternalistic decision making. (1st ed.). New Bury Park, CA: Sage Publications.

Collopy, B.J. (1988). Autonomy in long term care: Some crucial distinctions. The Gerontologist Society of America, 28(1),10-17.

Cox, J.L., Fox, M.D., \& Irwin, L. (1989), Driving and the elderly: A review of the literature. Physical and Occupational Therapy in Geriatrics, 7, 7-25.

Coy, J.A. (1989). Autonomy-based informed consent: Ethical implications for patient noncompliance. Physical Therapy, 69(10), 826-833.

Crisp, R. (1990). Return to work after spinal cord injury. Journal of Rehabilitation,(1), 28-35.

Decker, S.D., \& Schulz, R. (1985). Correlates of life satisfaction and depression in middle-aged and elderly spinal cord-injured persons. The American Journal of Occupational Therapy, 39(11), 740-745.

DiMatteo, M., \& DiNicola, D. (1982). The psychology of the medical practitioner's role. (1st ed.). New York: Pergamon.

DeVivo, M.J. (1997). Causes and costs of spinal cord injury in the United States. Spinal Cord, 35(1), 809-813.

Dew, M.A., Lynch, K., Ernst, J., \& Rosenthal, R. (1983). Reaction and adjustment to spinal cord injury: A descriptive study. Journal of Applied Rehabilitation Counseling, $14,32-29$

Fowler, J.F. (1993). Survey research methods. (2nd ed.). New Bury Park, CA: 
SAGE Publications, Inc.

Frankel, H.L., Coll, J.R., Charlifue, S.W., Whiteneck, G.G., Gardner, B.P., Jamous, M.A., Krishan, K.R., Nuseibeh, I., Savic, G., \& Sett, P. (1998). Long-term survival in spinal cord injury: A fifty year investigation. Spinal Cord, 36(1), 266-274.

Frank, R.G., Van Valin, P.H., \& Elliott, T.R. (1987). Adjustment to spinal cord injury: A review of empirical and nonempirical studies. Journal of Rehabilitation, 53(4), 43-48,

Galski, T., Bruno, R.L., \& Ehle, H.T. (1992). Driving after cerebral damage: A model with implications for evaluation. The American Journal of Occupational Therapy, 46(4), 324-331.

Galski, T., Ehle, H.T., \& Williams, B. (1997). Off-road driving evaluations for persons with cerebral injury: a factor analytic study of predriver and simulator testing. The American Journal of Occupational Therapy, 51(5), 352-359.

Gerhart, K.A., Johnson, R.L, \& Whiteneck, G.G. (1992). Health and psychosocial issues of individuals with incomplete and resolving spinal cord injuries.

Paraplegia, 30, 282-287.

Gillins, L. (1990). Yielding to age: When the elderly can no longer drive. The Journal of Gerontological Nursing, 16(11), 12-15.

Glasser, I., \& Adelman, A. (1991). Visions of liberty. (1st ed.). New York: Arcade Publishing, Inc.

Goleman, D. (1988, June 14). Erikson, in his own old age, expands his view of life. The New York Times, 3, 13-17.

Handler, B.S., \& Patterson, J.B. (1995). Driving after brain injury. Journal of 
Rehabilitation, $45,43-48$.

Heil, J. (1993, July 5). Automakers offer help to disabled. Automotive News, $\underset{507}{\longrightarrow} 24$

Horowitz, A., Silverstone, B.M., \& Reinhardt, J.P. (1991). A conceptual and empirical exploration of personal autonomy issues within family caregiving relationships. The Gerontologist, 31(1), 23-31.

Hutcherson, D.G. (1989). Self-monitoring of driving for the elderly: Evidence for use of a driving diary. Physical and Occupational Therapy in Geriatrics, 7, 171-201.

International Center for the Disabled. (1986). ICD survey of disabled Americans: bringing disabled Americans into the mainstream. (International Center for the Disabled). New York: Author.

Jameton, A. (1988). In the borderlands of autonomy: Responsibility in long term care facilities. The Gerontologist, 28(1), 18-23.

Jones, R., Giddens, H., \& Croft, D. (1983). Assessment and training of braindamaged drivers. The American Journal of Occupational Therapy, 37(11), 754-760.

Kelley, S.D., \& Lambert, S.S. (1992). Family support in rehabilitation: A review of research, 1980-1990. Rehabilitation Counseling Bulletin, 36(2), 98-118.

Kielhofner, G. (1985). Model of human occupation. (1st ed.). Baltimore, MD: Williams \& Wilkins.

Kiernat, J.M. (1987). Promoting independence and autonomy through environmental approaches. Topics in Geriatric Rehabilitation, 3(1), 1-6.

Koppa, R.J. (1990). State of the art in automotive adaptive equipment. Human Factors, 32(4), 439-455. 
Krause, J.S., \& Anson, C.A. (1997). Adjustment after spinal cord injury:

Relationship to participation in employment or educational activities. Rehabilitation Counseling Bulletin, 40(3), 202-214.

Krause, J. S. (1996). Employment after spinal cord injury: Transition and life adjustment. Rehabilitation Counseling Bulletin, 39(4), 244-255.

Langer, E., \& Rodin, J. (1976). The effects of choice and enhanced personal responsibility for the aged: A field experiment in an institutional setting. Journal of Personality and Social Psychology, 34, 191-198.

Lasfargues, J.E, Custis, D., Morrone, F., Carswell, J., \& Nguyen, T. (1995). A model for estimating spinal cord injury prevalence in the United States. Paraplegia, 33(1), $62-8$

Latson, L.F. (1987). Overview of disabled drivers' evaluation process. Physical Disabilities Special Interest Section Newsletter. The American Journal of Occupational Therapy 10(4).

Lillie, S.M. (1993). Evaluation for driving. (1st ed.). St. Louis, MO: MosbyYear Book.

Malick, M.H., \& Almasy, B.S. (1983). Assessment and evaluation: life work tasks. In Hopkins \& Smith (Ed.)., Willard and Spackman's occupational therapy. (7th ed.). Philadelphia: Lippincott.

May, T. (1998). Autonomy, authority and moral responsibility. (1st ed.). Norwell, MA: Kluwer Academic Publishers.

Meltzoff, J. (1998). Critical thinking about research: Psychology and related fields. (1st ed.). Washington, D.C.: American Psychological Association. Mish, F. (Ed.). (1998). Merriam-Webster's collegiate dictionary (10th ed.). 
Springfield, MA: Merriam-Webster, Inc.

Murphy, R.F. (1990). The body silent. (1st ed.). New York: WW Norton.

Murtaugh, M. \& Zetlin, A.G. (1990). The development of autonomy among learning handicapped and nonhandicapped adolescents: A longitudinal perspective. Journal of Youth and Adolescence, 19(3), 245-255.

Park, D.C., \& Smith, A.D. (1991). Importance of basic and applied research from the viewpoints of investigators in the psychology of aging. Experimental Aging Research, 17(2), 79-81.

Pedretti, L.W. (1996). Occupational therapy: Practice skills for physical dysfunction. (4th ed.). Missouri: Mosby.

Post, M., Asbeck, F., Dijk, A., Schrijvers. (1997). Services for spinal cord injured: Availability and satisfaction. Spinal Cord, 35, 109-115.

Ryden, M. (1984). Morale and perceived control in institutionalized elderly. Nursing Research, 33(3), 130-136.

Schieber, F. (1994). High-priority research and development needs for maintaining the safety and mobility of older drivers. Experimental Aging Research, 20 . $35-43$.

Sprigle, S., Morris, B.O., Nowachek, G., \& Karg, P.E. (1995). Assessment of the evaluation procedures of drivers with disabilities. The Occupational Therapy Journal of Research, 15(3), 147-163.

Stein, F., \& Cutler, S.K. (1996). Clinical tesearch in allied health and special education. (3rd ed.). San Diego, CA: Singular Publishing Group, Inc.

Systems Technology Inc., (1997). (On-line). Available: www.systemstech 
The American Occupational Therapy Association. (1993). Position paper: purposeful activity. The American Journal of Occupational Therapy, 47, 1081-1082.

The American Occupational Therapy Association. (1996). The occupational therapy manager. (Rev, ed.). Bethesda, MD: The American Occupational Therapy Association, Inc.

U.S. Census Bureau. (1990). (On-line). Available: www.census.gov

West, M., Hock, T., Wittig, K., \& Dowdy, V. (1998). Getting to work: Training and support for transportation needs. Journal of Vocational Rehabilitation, 10, 159-167.

Wilson, D.J., McKenzie, M.W., \& Barber, L.M. (1984). Spinal cord injury: a treatment guide for occupational therapists. (Rev.ed.). Thorofare, NJ: Slack.

World Health Organization. (1980). International classifications of impairments, disabilities, and handicaps: A manual of classification relating to the consequences of disease. Geneva: Author. 
APPENDICES 


\section{APPENDIX A}

\section{Cover Letter}

May 23, 1999

Dear participant,

My name is Alice Giron and I am a occupational therapy master's degree student at Florida International University. I am conducting a study to explore the importance and value of being able to drive a motor vehicle to persons with spinal cord injuries. Please answer all of the survey questions to the best of your ability. All of your responses will remain anonymous as no name will appear on the survey form. The survey will take approximately 10 to 15 minutes to complete. Kindly return the survey in the selfaddressed envelope provided by July 15, 1999.

I would like to take this opportunity to thank you for your support in helping me to achieve my educational goals. Your help and time will be invaluable to my study.

Sincerely,

Alice Giron 


\section{APPENDIX B \\ Questionnaire}

Please answer the following questions by filling in the correct responses. Please select only one choice for each question.

1. How old are you?

2. What is your gender? $\square$ Male $\square$ Female

3. Which of the following best describes your racial or ethnic background?
$\square$ Asian
$\square$ Hispanic
$\square$ Black/African American
$\square$ Native American
$\square$ White/Caucasian
$\square$ Other (Please specify):

4. What level is your spinal cord lesion?
$\square \mathrm{C} 1-\mathrm{C} 5$
$\square$ T9-T12
$\square \mathrm{C} 6-\mathrm{C} 8$
$\square$ L1-L5
$\square \mathrm{T} 1-\mathrm{T} 5$
$\square$ S1-S5
$\square$ T6-T8

5. What is your marital status?
$\square$ Never Married
$\square$ Divorced
$\square$ Widowed
$\square$ Married
$\square$ Separated

6. What is the highest level of education you completed?
$\square$ Elementary
$\square$ Some college
口 Some high school
$\square$ College graduate
$\square$ High school graduate
$\square$ Graduate school

7. What is your current work status?
$\square$ Working full-time
$\square$ Retired and not employed
$\square$ Working part-time
$\square$ Retired and employed
$\square$ Unemployed
$\square$ Student
$\square$ Homemaker
$\square$ Other: (Please specify) 
8. Do you own a vehicle or have access to one? $\square$ Yes $\square$ No

9. Are there any adaptations to your vehicle that allow you to drive? $\square$ Yes $\square$ No

10. If you do own a vehicle or have access to one, what kind is it?
$\square 2$ door sedan
$\square$ Sports utility vehicle
$\square 4$ door sedan
$\square$ Jeep
口 Van
$\square$ Other: (Please specify)

11. Before your injury, disability or other condition that caused your inability to drive, how did you usually get around?

$\square$ Drove vehicle

$\square$ Public transportation

$\square$ Friends or family would drive

$\square$ Other: (Please specify)

12. How do you currently get around?

$\square$ Drive vehicle

$\square$ Public transportation

$\square$ Friends or family will drive

$\square$ Other: (Please specify)

13. How often did you drive before your injury, disability or other condition?

$\square$ Once or more a day

$\square$ Weekly

Once a month

a More than once a week

a More than once a month

$\square$ I did not drive

14. How often are you currently driving?
$\square$ Once or more a day
$\square$ Once a month
$\square$ Weekly
$\square$ More than once a month
$\square$ More than once a week
$\square$ I do not drive 
Please answer the following questions by marking the box that best corresponds to your answer.

$$
\begin{aligned}
& \text { The five choices listed include: } \\
& \mathbf{S A}=\text { Strongly Agree } \\
& \mathbf{A}=\text { Agree } \\
& \mathbf{U}=\text { Undecided (Neither agree or disagree) } \\
& \mathbf{D}=\text { Disagree } \\
& \mathbf{S D}=\text { Strongly Disagree }
\end{aligned}
$$

\begin{tabular}{|c|c|c|c|c|c|}
\hline Questions & $\mathbf{S A}$ & $\mathbf{A}$ & UD & $\mathbf{D}$ & SD \\
\hline 15. Being able to drive a vehicle is very important to me. & & & & & \\
\hline 16. I feel comfortable and confident driving. & & & & & \\
\hline 17. I am independent in most or all of my daily activities. & & & & & \\
\hline $\begin{array}{l}\text { 18. I feel more in control of my life when I can drive } \\
\text { myself to complete work tasks. }\end{array}$ & & & & & \\
\hline $\begin{array}{l}\text { 19. I feel more in control of my life when I can drive } \\
\text { myself to obtain medical and self-care needs. }\end{array}$ & & & & & \\
\hline $\begin{array}{l}\text { 20. I feel more in control of my life when I can drive } \\
\text { myself to sports, musical events, and other } \\
\text { recreational activities. }\end{array}$ & & & & & \\
\hline $\begin{array}{l}\text { 21. I feel more in control of my life when I can drive } \\
\text { myself to do food, clothes, and other shopping. }\end{array}$ & & & & & \\
\hline 22. Overall, I feel confident and in control of my life. & & & & & \\
\hline $\begin{array}{l}\text { 23. When I lost the ability to drive, I felt like many of my } \\
\text { freedoms had been taken away from me. }\end{array}$ & & & & & \\
\hline
\end{tabular}

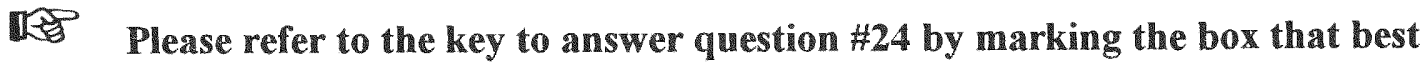
corresponds to your answer.

$100 \%=$ It improves my life on a daily basis

$75 \%=$ It improves my life 5-6 days a week

$50 \%=$ It improves my life 3-4 days a week

$25 \%=$ It improves my life 1-2 days a week

Less than $25 \%=$ It improves my life occasionally but not on a consistent basis

24. Being able to drive again or for the first time has improved my life by.... $100 \%$ $75 \% \quad 50 \%$ $25 \%$ $<25 \%$

Thank you for your cooperation! 